\title{
Growth and Land Use with Agriculture and Industry
}

\author{
Wei-Bin Zhang
}

\author{
Ritsumeikan Asia Pacific University, Oita-Ken, Japan
}

\begin{abstract}
This paper develops an economic growth model with economic structure and geography. The economy consists of one agricultural and one industrial sector and economic geography consists of urban and rural areas. The model synthesizes the main ideas in the Solow growth, the Alonso urban, and the von-Thünen's agricultural models in a compact framework. We simulate the model. We demonstrate that the economic geography has a unique equilibrium point with the specified parameter values. We examine changes in the preference, productivity, urban and regional amenities, transportation conditions, the population, and land endowment upon the long-term economic growth, structure, and geography.
\end{abstract}

Keywords: Urban dynamics, capital accumulation, land rent, residential distribution, Solow's growth model, Alonso's urban model, von-Thünen's agricultural model.

\section{INTRODUCTION}

Over the past two decades, issues related to growth with economic geography have increasingly caused attention in economics (Krugman, 1991, 1998; Henderson and Thisse, 2004; Capello and Nijkamp, 2004). Yet, it may be argued that economic geography still needs an analytical framework for spatial evolution and growth with capital accumulation. As early as in 1980, Arnott (1980: 53) points outs: "In the last decade the static theory of residential urban location and land use has been extensively developed. The theory has generated many useful insights, but because it ignores growth and durability of housing and urban infrastructures there are many urban phenomena it cannot explain." Only a few formal urban economic models can explain interactions, for instance, between economic growth and land rent. Housing markets are obviously interacting with economic growth. It is imperative to build models with endogenous housing markets and wealth accumulation on microeconomic foundation in order to explain dynamic interactions. Economics needs an analytical framework in which interactions among economic growth, division of labor, and resource distribution over time and space can be treated as a consistent manner. For instance, the development of agricultural sector is closely related to the development of other economic sectors and land use distribution is dependent upon the interdependence of different economic sectors. Moreover, these interactions are influenced by resources, preferences and technological changes. Land should affect economic structure. The propensity to save should influence economic growth.

*Address correspondence to this author at the Ritsumeikan Asia Pacific University, Jumonjibaru, Beppu-Shi, Oita-Ken, 874-8577, Japan; Tel: (81) 97778 1020; Fax: (81) 97773 9787; E-mail: wbz1@apu.ac.jp

E-ISSN: $1929-7092 / 14$
Technological change should cause changes in productivities and urbanization. All these important elements and their interactions should be analyzed in an integrated framework.

The purpose of this paper is to develop an economic growth model with economic structure and geography to explain dynamic interdependence among growth, sectoral division of labor, and economic geography. The economy consists of one agricultural and one industrial sector and economic geography consists of urban and rural areas. There are mainly two kinds of land use. One is agricultural land use and the other is residential land use. Our model synthesizes the main ideas in the Solow growth, the Alonso urban, and the von-Thünen's agricultural models in a compact framework. It is well known that most of the models in the neoclassical growth theory model are extensions and generalizations of the pioneering works of Solow in 1956. The Solow model is sometimes referred as to the Sowlo-Swan model because Swan (1956) proposed a model similar to the Solow model. The model has played an important role in the development of economic growth theory by using the neoclassical production function and neoclassical production theory. The Solow model has been extended and generalized in numerous directions (e.g., Burmeister and Dobell, 1970). But almost all these studies do not have spatial dimension (for instance, Baldwin and Martin, 2004; Capello and Nijkamp, 2004). The purpose of this study is to introduce the neoclassical growth theory into spatial economics. As argued by Lucas (1988), it is necessary to analyze urban configuration and economic growth as a connected whole. Partial equilibrium models fail to explain interactions among various sectors of economic activities over time and space. For instance, current urban economics cannot properly address issues related to how economic 
growth will affect residential distribution and land rent. Although some attempts have been to apply the neoclassical growth theory to address urban growth issues, these models do not take account of land and agriculture (Richardson, 1973; Henderson, 1985; Henderson and Thisse, 2004). This study tries to introduce agricultural sector to growth theory with an alternative approach to consumer behavior.

A main feature of agricultural activities is that land is used extensively. In our study, the agricultural sector is a simplified version of von Thünen's model of an isolated state (Mundlak, 2000). It should be noted that although Mundlak introduces a two-sector model of industry and agriculture, the model is essentially the Uzawa two-sector model, which lacks a rational mechanism for individual choice and does not properly take account of space. As pointed out by Blaug (1985), the history of location theory begins with the publication of von Thünen's Der Isolierte Staat (The Isolated State) in 1826. Von Thünen was concerned with the problem of agricultural activities which center on the competition of land use. He provided the classical analysis of allocation of land among competing agricultural activities. He started to construct the isolated state economy with a very large town in the center of a fertile plain. For convenience of analyzing issues related to transportation, the plain does not any navigable rivers or canals. The soil is of uniform fertility everywhere. The plain is so huge that the state is absolutely isolated from the rest of the world and the state is surrounded by uncultivated wilderness. There is only a single city where all manufacturing products are produced. The city depends entirely on the surrounding countryside for its supply of agricultural products. The question is how under these circumstances will agriculture be developed and how will the distance from the city affect the agricultural sector when these are chosen in the optimal manner? Von Thünen showed that the town would be surrounded by agricultural rings: each ring cultivates a specific crop associated with the highest bid rent over the ring. Nevertheless, he did not develop an economic theory to see how agricultural production and rural area is interrelated to economic growth and urbanization.

Isard (1956) noticed that the ideas of von Thünen could be reinterpreted in the context of urban land-use. Since then, there are some works, which mark a conceptual transition between the earlier work of land economists and modern urban economists (Beckmann, 1957, Mohring, 1961, Wingo, 1961, Muth, 1961). The availability of a well-developed microeconomic theory provided the theoretical foundations for the growth of modern urban economics. Beckmann (1957) studied the determination of equilibrium residential land rents and quantities in a monocentric city, where all employment and services are concentrated in the CBD (central business district) surrounded by a residential area. But it may be argued that the development of modern urban economics has been strongly influenced by the work of Alonso (1964). In his bid-rent theory, Alonso pioneered the adaptation of von Thünen's work on an urban context. The central market was replaced by a central business district, and agricultural products by alternative urban lands. According to Papageorgiou and Pines (1999), Alonso's greatest contribution was his proposal for the matching between spatial analysis and microeconomic theory that was necessary for the development of modern urban economics. Similar to the Solow model for neoclassical growth model, the Alonso model provides a simple mathematical structure based on which many articles have been published. The Alonso model is concerned with urban land use and market land prices. In its simple form, the model of monocentric city assumes that all economic activities are concentrated in central business districts, The model explains pattern formation of the residential land use around the CBD. The price of land, the density of land use, and the equilibrium locations of the urban population are endogenously determined by the model. This residential part of our model is based on Alonso's urban model.

The objective of this paper is to study growth with economic geography. We are concerned with the residential land use pattern and determination of industrial and agricultural production, capital accumulation, sectoral division of labor, capital distribution, and land rent over time and space. The model is a one-dimensional model of residential and agricultural location with a central business center. The study is organized as follows. Section 2 defines the basic model. Section 3 shows how we solve the spatial economic equilibrium and demonstrate the existence of a unique equilibrium point. Sections 4 to 5 examine the effects of changes in productivity, amenity, transportation, preference, population and territory upon the spatial economic structure. Section 6 concludes the study. The appendix proves the main results in Section 3.

\section{THE MODEL}

We are concerned with an isolated economy. The economy consists of two - industrial and agricultural - 
sectors. The industrial sector produces industrial goods, which are freely traded in national market. It is a capital commodity used both for investment and consumption. The agricultural sector produces agricultural goods, which is used for consumption of the population. Agricultural goods are assumed to be consumed simultaneously as they are produced. We neglect possible storage. We assume perfect capital mobility. As far as urban structures are concerned, we follow the standard residential land-use model. The basic features of this model are that the city is built on a linear space as explained below. All residents in the economy work in the CBD. People travel only between their homes and the CBD. Travel is equally costly in terms of time or/and money in the two directions. An individual may reside at only one location. The only spatial characteristic of any location that directly matters is the distance from the city center. Due to the complexity of taking both space and time in a general equilibrium framework, at this initial stage we simplify the structure of the isolated economic system. The population is homogenous. It should be noted that Beckman (1969) introduced heterogeneous households into urban models (see also, Solow, 1973; Beckmann and Papageorgiou, 1989; Anas, 1990; Tabuchi and Thisse, 2002). Steigum (1984) studies labor transfer processes in the context of a small open two-sector economy with sticky real wages and labor transfer costs. Steigum considers heterogeneous labor and introduces training costs in labor transfer processes in terms of output foregone when workers already possessing industry-specific knowledge are training new workers. The households achieve the same utility level regardless of where they locate. All the markets are perfectly competitive. The system is geographically linear and consists of three parts - the $\mathrm{CBD}$, the urban residential area, and the rural area. The system consists of a finite strip of land extending from the CBD with constant unit width. We assume that the industrial sector is concentrated in the CBD. The workers employed by the industrial sector occupy the residential area. We assume that the CBD is located at the left-side end of the linear territory, as illustrated in Figure 1. As we will get the same conclusions if we locate the CBD at the center of the linear system, the specified urban configuration will not affect our discussion. The rural area is located beyond the urban area. We neglect any internal complexity of the rural area. The farmers live whether they work. There is no travel cost for farmers in terms of time and money. The rural land is distributed between dwelling and farming. The boundary between the urban and rural areas and the land distribution between dwelling and farming use in the rural area are all determined by the market mechanism.

The industrial production is the same as that in the one-sector neoclassical growth model. We assume that the industrial product can be either invested or consumed. We assume that the total labor force is fully employed by the industrial and agricultural sectors. We select industrial goods to serve as numeraire. As we assume that the transportation cost of workers to the city is dependent on the travel distance, land rent for housing should be spatially different. First, we introduce

$N$ and $\bar{L}$ - the fixed population and land of the economy;

$\bar{L}_{i}(t)$ and $\bar{L}_{a}(t)$ - the urban residential land and rural land, respectively, at time $t$;

$i, a-$ subscript index for the industrial and agricultural sectors, respectively;

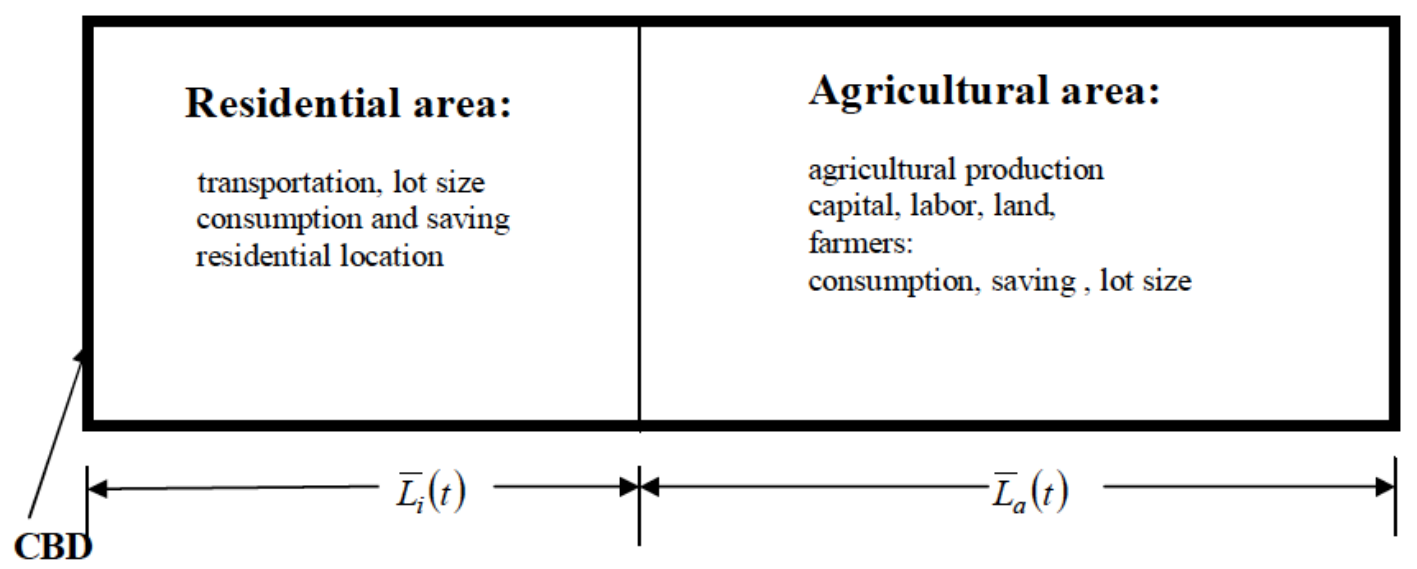

Figure 1: The Spatial Configuration of the Isolated State. 
$F_{j}(t)$ - the output level of sector $j, j=i, a$, at time $t$

$K_{j}(t)$ and $N_{j}(t)$ - the capital stocks and labor force employed by sector $j, j=i, a$, at time $t$;

$w_{j}(t)$ - the wage rate of sector $j, j=i, a$; and

$p(t)$ and $r(t)$ — the price of agricultural goods and the rate of interest.

\section{Industrial Sector}

We assume that industrial production is carried out by combination of capital and labor force in the form of $F_{i}\left(K_{i}(t), N_{i}(t)\right)$, where $F_{i}$ is the output of the industrial sector. Assume $F_{i}$ to take on the Cobb-Douglas form

$F_{i}(t)=A_{i} K_{i}^{\alpha_{i}}(t) N_{i}^{\beta_{i}}(t), A_{i}, \alpha_{i}, \beta_{i}>0, \alpha_{i}+\beta_{i}=1$.

It should be marked that as a referee points out, the assumption of constant returns to scale is strict. For explaining the existence of the CBD, it is usual to assume scale economies in production in order to generate an incentive to concentrate economic activity in the presence of transportation costs. There are different ways of introducing scale economies in the literature. For instance, if we specify production function as $F_{i}=G\left(F_{i}\right) K_{i}^{\alpha_{i}} N_{i}^{\beta_{i}}$, where $G$ measures effects of changeable scale effects. It can be seen that if we specify $G=F_{i}^{\eta}, \quad 0<\eta<1$, then we can still analyze the behavior in almost the same procedure as in the reminder of this paper. Indeed, the stability properties of the model will be affected and comparative statics results will be more complicated, depending on the value of $\eta$. For simplicity of analysis, we are only concerned with constant returns to scale with the Cobb-Douglas specification. Markets are competitive; thus labor and capital earn their marginal products, and firms earn zero profits. The rate of interest, $r(t)$, and wage rates, $w_{j}(t)$, are determined by markets. Hence, for any individual firm $r(t)$ and $w_{j}(t)$ are given at each point of time. The industrial sector chooses the two variables, $K_{i}(t)$ and $N_{i}(t)$, to maximize its profit. The marginal conditions are given by

$r(t)+\delta_{k}=\frac{\alpha_{i} f_{i}(t)}{k_{i}(t)}, w_{i}(t)=\beta_{i} f_{i}(t)$,

where $\delta_{k}$ is the depreciation rate of physical capital and $f_{i}(t) \equiv A_{i} k_{i}^{\alpha_{i}}(t), \quad k_{i}(t) \equiv \frac{K_{i}(t)}{N_{i}(t)}$

\section{Agricultural Sector}

We assume that agricultural production is carried out by combination of capital, labor force and land as follows

$$
\begin{aligned}
& F_{a}(t)=A_{a} K_{a}^{\alpha_{a}}(t) N_{a}^{\beta_{a}}(t) L_{0 a}^{\varsigma}(t), \\
& A_{a}, \alpha_{a}, \beta_{a}, \varsigma>0, \alpha_{a}+\beta_{a}+\varsigma=1 .
\end{aligned}
$$

where $L_{0 a}(t)$ is the land employed by the agricultural sector and $A_{a}, \alpha_{a}, \beta_{a}$, and $\varsigma$ are parameters. The marginal conditions are given by

$$
\begin{aligned}
& r(t)+\delta_{k}=\frac{\alpha_{a} p(t) f_{a}(t)}{k_{a}(t)}, \\
& w_{a}(t)=\beta_{a} p(t) f_{a}(t), \quad R_{a}(t)=\frac{\varsigma p(t) f_{a}(t)}{l_{a}(t)},
\end{aligned}
$$

where $R_{a}(t)$ is the land rent in the rural urban area and

$f_{a}(t) \equiv A_{a} k_{a}^{\alpha_{a}}(t) l_{a}^{\varsigma}(t), k_{a}(a) \equiv \frac{K_{a}(t)}{N_{a}(t)}, l_{a}(t) \equiv \frac{L_{0 a}(t)}{N_{a}(t)}$

As we neglect transport costs of agricultural goods and farmers' travels to work costs neither in terms of money nor time, the land rent in any location of the rural area is the same. Moreover in von Thünen's model, the agricultural land rent is a function of distance to the center, given that crops are transported to the center. We now describe behavior of households. First, we introduce

$\omega$ - the distance from the CBD to a point in the urban residential area, $0 \leq \omega \leq \bar{L}_{i}(t)$;

$R_{i}(\omega, t)$ - the land rent at location $\omega$;

$\bar{k}_{i}(\omega, t), q_{i}(\omega, t), c_{i}(\omega, t)$ and $s_{i}(\omega, t)$ - the wealth, consumption level of agricultural goods, consumption level of industrial goods, and the saving of the representative household at location $\omega$;

$\bar{k}_{a}(t), \quad q_{a}(t), \quad c_{a}(t)$ and $s_{a}(t)$ - the wealth, consumption level of agricultural goods, consumption level of industrial goods, and the saving of the representative household in the rural area; 
$n(\omega, t)$ and $L_{i}(\omega, t)$ - the residential density and the lot size of the urban household at location $\omega$;

$L_{a}(t)$ — the lot size of the rural household;

$K(t)$ — the total capital stock of the economy.

\section{Behavior of Urban Households}

According to the definitions of $L_{i}$ and $n$, we have

$n(\omega, t)=\frac{1}{L_{i}(\omega, t)}, 0 \leq \omega \leq \bar{L}_{i}(t)$

Each worker may get income from land ownership, wealth ownership and wages. In order to define incomes, it is necessary to determine land ownership structure. It can be seen that land properties may be distributed in multiple ways under various institutions. To simplify the model, we assume the land is equally owned by the population. This implies that the revenue from land is equally shared among the population. Another two popular assumptions in the literature of spatial economics are the absentee landownership and the public ownership (see, Fujita, 1999, Fujita and Thisse, 2002). In the former, land is owned by absentee landlords who spend their land incomes outside the economic system. In the latter, the city government rents the land from the landowners at certain rent and sublets it to households at the market rent, using the net revenue to subsidize city residents equally. The total land revenue, $\bar{R}(t)$, from the sum of the land rents from the urban area and rural area. That is

$$
\bar{R}(t)=\int_{0}^{\bar{L}_{i}(t)} R_{i}(\omega, t) d \omega+R_{a}(t) \bar{L}_{a}(t),
$$

in which $\int_{0}^{\bar{L}_{i}(t)} R_{i}(\omega, t) d \omega$ and $R_{a}(t) \bar{L}_{a}(t)$ are respectively the total urban and rural land rents. The income from land per household, $\bar{r}(t)$, is given by

$\bar{r}(t)=\frac{\bar{R}(t)}{N}$.

Consumers make decisions on choice of lot size, consumption level of commodity as well as on how much to save. This study uses the approach to consumers' behavior proposed by Zhang in the early 1990s. This approach makes it possible to solve many national, international, urban, and interregional economic problems, such as growth problems with heterogeneous households, multi-sectors, and preference changes, which are analytically intractable by the traditional approaches in economics. Each urban household at $\omega$ obtains income

$$
y_{i}(\omega, t)=r(t) \bar{k}_{i}(\omega, t)+w_{i}(t)+\bar{r}(t), 0 \leq \omega \leq \bar{L}_{i}(t),
$$

from the interest payment, $r \bar{k}_{i}$, and the wage payment, $w_{i}$, and the land rent income, $\bar{r}$. We call $y_{i}(\omega, t)$ the current income of the representative urban household in the sense that it comes from the household's wage and earnings from ownership of wealth. The sum of income that consumers are using for consuming, saving, or travels are not necessarily equal to the current income because consumers can sell wealth to pay, for instance, the current consumption if the current income is not sufficient for buying food and touring the country. Retired people may live not only on the interest payment but also have to spend some of their wealth. The total value of the wealth that a consumer at location $\omega$ can sell to purchase goods and to save is equal to $p_{i}(t) \bar{k}_{i}(\omega, t)$, with $p_{i}(t)=1$ at any $t$. Here, we assume that selling and buying wealth can be conducted instantaneously without any transaction cost. The disposable income is then equal to

$\hat{y}_{i}(\omega, t)=y_{i}(\omega, t)+\bar{k}_{i}(\omega, t)$.

The disposable income is used for saving and consumption. It should be noted that the value, $\bar{k}_{i}(\omega, t)$, (i.e., $\left.p_{i}(t) \bar{k}_{i}(\omega, t)\right)$, in the above equation is a flow variable. Under the assumption that selling wealth can be conducted instantaneously without any transaction cost, we may consider $\bar{k}_{i}$ as the amount of the income that the consumer at $\omega$ obtains at time $t$ by selling all of his wealth. Hence, at time $t$ the consumer has the total amount of income equaling $\hat{y}_{i}$ to distribute between consuming and saving. It should also be remarked that in the growth literature, for instance, in the Solow model, the saving is out of the current income; $y_{i}$, while in this study the saving is out of the disposable income which is dependent both on the current income and wealth. The implications of this approach are similar to those in the Keynesian consumption function and models based on the permanent income hypothesis, which are empirically much more valid than the approaches in the Solow model or the in Ramsey model. The approach to household behavior in this study is discussed at length by Zhang $(2005,2008)$. It should be remarked that Zhang has also examined the relations between his approach and the Solow growth theory, the Ramsey growth theory, the permanent income hypothesis, and the Keynesian consumption function, which are the 
main approaches to household behavior with wealth accumulation in the modern economic growth theory in details. It can be shown that the behavior generated by the traditional approaches can also be observed in Zhang's approach by specifying certain patterns of preference changes.

At each point of time, a consumer at location $\omega$ distributes the total available budget among the leisure time, $T_{h}(\omega)$, lot size, $l_{i}(\omega, t)$, saving, $s_{i}(\omega, t)$, consumption of agricultural goods, $q_{i}(\omega, t)$, consumption of industrial goods, $c_{i}(\omega, t)$. Here, we assume that the leisure is only dependent on the residential location as the work time is fixed and equal for each household, in disregard of residential location. After the work time is decided, the households decide the time distribution between leisure and travel to work. This assumption can be relaxed by considering work time, $T_{w}(\omega)$, an endogenous variable. When the labor time is endogenous, the leisure time is equal to the total available time minus the travel time and labor time. In this case, the total labor input is given by

$$
\int T_{w}(\omega) n(\omega) d \omega
$$

If we assume that the wage rate per unit time is equal for all the workers, then the equilibrium problem is solvable. Nevertheless, if we assume that the wage rate is distance-dependent (this is possible in Japan as companies may pay travel costs according to residential location), analysis may become more complicated. As we assume that the travel time from the CBD to the residential location is only related to the distance and neglect any other effects such on technological change, infrastructure improvement, and congestion on the travel time form the CBD to the residential area, the leisure time, which is equal to the fixed total time minus the travel time, is only related to location. Let $T_{0}$ and $\Gamma(\omega)$ respectively stand for the total available time for travel and leisure and the time spent on traveling between the residence and CBD. We have

$T_{h}(\omega)=T_{0}-\Gamma(\omega)$.

We assume that pecuniary travel cost, $\Gamma_{c}(\omega)$, is dependent only on the distance. In reality, transport mode is an endogenous variable, which implies that like housing, transportation service should enter the utility function. Transportation cost is actually related to income (see, for instance, Train and McFadden, 1978, Rietveld et al., 2003, De Palma, Kilani, and Lindsey, 2005). The pecuniary travel cost increases in $\omega$. The budget constraint is given by

$$
\begin{aligned}
& p(t) q_{i}(\omega, t)+c_{i}(\omega, t)+R_{i}(\omega, t) L_{i}(\omega, t) \\
& +s_{i}(\omega, t)+\Gamma_{c}(\omega)=y_{i}(\omega, t) .
\end{aligned}
$$

Equation (10) means that the consumption and saving exhaust the consumers' disposable personal income.

As argued by Glaeser, Kolko, and Saiz (2001), consumption amenities have increasingly played more important role in urban formation. In this study, we incorporate amenity into the consumer location decision by assuming that amenity is a function of residential density. This study does not take account of externalities for producers. For instance, firms often prefer to locate to other firms. In the literature of urban economics, various externalities have been analyzed (Henderson, 1974; Upton, 1981; Zhang, 1993, 1994; Abdel-Rahman, 2004). Distance from the CBD reflects two elements: the inconvenience of the distance and the value of the amenity of the surrounding area. Many kinds of externalities may actually exist at any location. Some may be historically given, such as historical buildings and climate; others such as noise and cleanness, may be endogenously determined by the location of residents. Households may prefer a lowdensity residential area to a high one, as there tend to have more green, less noise, more cleanness and more safety in a low-density area. Nevertheless, there are other factors, such as social interactions, which may make high-density area attractive. This study considers that residential densities may have positive or negative agglomeration effects. We specify the amenity, $\theta_{i}(\omega, t)$, at $\omega$ as follows

$\theta_{i}(\omega, t)=\bar{\theta}_{i} n^{a}(\omega, t), \bar{\theta}_{i}>0$.

The function $\theta_{i}(\omega, t)$ implies that the amenity level at location $\omega$ is related to the residential density at the location. This specified form is a limited case. Locational amenities or disamenities are not only affected by the residential density at the location. For instance, possible social contacts of any individual are spread over the whole space. Air pollution is not limited to locals. It should be noted that if $a=0$, amenity is identical over time and space.

Location choice is closely related to the existence and quality of such physical environmental attributes as open space and noise pollution as well as social environmental quality. We assume that utility level, $U_{i}(\omega, t)$, of the household at location $\omega$ is dependent on $\theta_{i}(\omega, t), \quad T_{i}(\omega), \quad q_{i}(\omega, t), \quad c_{i}(\omega, t), \quad L_{i}(\omega, t)$, and $s_{i}(\omega, t)$ as follows 


$$
\begin{aligned}
& U_{i}(\omega, t)=\theta_{i}(\omega, t) T_{h}^{\sigma}(\omega) q_{i}^{\mu_{0}}(\omega, t) c_{i}^{\xi_{0}}(\omega, t) L_{i}^{\eta_{0}} \\
& (\omega, t) s_{i}^{\lambda_{0}}(\omega, t), \sigma, \mu_{0}, \xi_{0}, \eta_{0}, \lambda_{0}>0,
\end{aligned}
$$

in which $\sigma, \mu_{0}, \xi_{0}, \eta_{0}$, and $\lambda_{0}$ are the urban household's elasticity of utility with regard to leisure time, agricultural goods, industrial goods, housing, and saving at $\omega$. We call $\sigma, \mu_{0}, \xi_{0}, \eta_{0}$, and $\lambda_{0}$ propensities to use leisure time, to consume agricultural goods, to consume industrial goods, to consume housing, and to hold wealth, respectively. It should be noted that our approach to household behavior is different from the discounted utility which has been the main framework of choice for intertemporal decisions in the literature of theoretical economics (Zhang, 2005). It is worthwhile to cite from Samuelson's following cautions about this traditional approach (Samuelson, 1937: 159): "It is completely arbitrary to assume that the individual behaves so as to maximize an integral of the form envisaged in [the discounted utility model]." The Ramsey framework has not been proved to be effective when we take account of variations in households' preferences. As empirical studies have convinced existence of great differences in impatience among households and the Ramsey approach proves futile for dealing with the issues, it is necessary to search alternative ways to explain the reality. In fact, as shown in a survey on studies of estimating individuals' discount rates by Frederick, Loewenstein, and O'Donoghue (2002) rates differ dramatically across studies, and within studies across individuals. It is estimated, for instance, by Warner and Pleeter (2001) that individual discount rates vary between 0 and 70 percent per year. The studies, for instance, by Rader (1981), also hold that there is no reason to believe that different consumers have identical time preferences for utility streams. It should be remarked that Becker (1992) first observed that if individuals have heterogeneous constant rates of impatience, the representative agent will not in general use a constant rate to discount the future. As observed by Frederick, Loewenstein, and O'Donoghue (2002: 393-384): "The [discounted utility] model, which continues to be widely used by economists, has little empirical support. Even its developers - Samuelson, who originally proposed the model, and Koopmans, who provided the first axiomatic derivation - had concerns about its descriptive realism, and it was never empirically validated as the appropriate model for intertemporal choice. ... [D]eveloping descriptively adequate models of interremporal choice will not be easy." This paper uses an alternative utility function.

Maximizing $U_{i}(\omega, t)$ subject to the budget constraint (10) yields

$$
\begin{aligned}
& q_{i}(\omega, t)=\frac{\mu \hat{y}_{i}^{*}(\omega, t)}{p(t)}, c_{i}(\omega, t)=\xi \hat{y}_{i}^{*}(\omega, t), \\
& L_{i}(\omega, t)=\frac{\eta \hat{y}_{i}^{*}(\omega, t)}{R_{i}(\omega, t)}, s_{i}(\omega, t)=\lambda \hat{y}_{i}^{*}(\omega, t),
\end{aligned}
$$

in which $\hat{y}_{i}^{*}(\omega, t) \equiv \hat{y}_{i}(\omega, t)-\Gamma_{c}(\omega)$ and

$$
\begin{aligned}
& \mu \equiv \rho \mu_{0}, \xi \equiv \rho \xi_{0}, \eta \equiv \rho \eta_{0}, \lambda \equiv \rho \lambda_{0}, \\
& \rho \equiv \frac{1}{\mu_{0}+\xi_{0}+\eta_{0}+\lambda_{0}} .
\end{aligned}
$$

According to the definition of $s_{i}(\omega, t)$, the wealth accumulation for the household at location $\omega$ is given by

$$
\bar{k}_{i}(\omega, t)=s_{i}(\omega, t)-\bar{k}_{i}(\omega, t), 0 \leq \omega \leq L .
$$

\section{Behavior of Rural Households}

Similar to behavior of urban households, we now describe behavior of rural households. A rural household's current income, $y_{a}(t)$, and disposable income, $\hat{y}_{a}(t)$, are given as

$$
\begin{aligned}
& y_{a}(t)=r(t) \bar{k}_{a}(t)+w_{a}(t)+\bar{r}(t), \\
& \hat{y}_{a}(t)=y_{a}(t)+\bar{k}_{a}(t) .
\end{aligned}
$$

The budget constraint is given by

$$
p(t) q_{a}(t)+c_{a}(\omega, t)+R_{a}(\omega) L_{a}(t)+s_{a}(t)=\hat{y}_{a}(t) .
$$

Utility level, $U_{a}(t)$, of the rural household is dependent on consumption of agricultural goods, $q_{a}(t)$, consumption of industrial goods, $c_{a}(t)$, lot size, $L_{a}(t)$, and saving, $s_{a}(t)$, as follows

$$
U_{a}(t)=\theta_{a} q_{a}^{\mu_{0}}(t) c_{a}^{\xi_{0}}(t) L_{a}^{\eta_{0}}(t) s_{a}^{\lambda_{0}}(t), \mu_{0}, \xi_{0}, \eta_{0}, \lambda_{0}>0 .
$$

We call $\theta_{a}$ the amenity level of the agricultural area. In fact, the agricultural sector may bring about either amenity or disamenity. For instance, animal agriculture tends to be associated with disamenity. Ready and Abdalla (2005: 314) observe, "positive externalities such as open space, wildlife habitat, and groundwater recharge are one motivation behind attempts to sprawl farmland and discharge urban sprawl through mechanisms such as preferential tax assessment, purchase of development rights, restrict zoning, and 'smart growth' planning approaches." Maximizing $U_{a}(t)$ subject to the budget constraint (16) yields 
$q_{a}(t)=\frac{\mu \hat{y}_{a}(\omega, t)}{p(t)}, c_{a}(t)=\xi \hat{y}_{a}(t)$

$L_{a}(t)=\frac{\eta \hat{y}_{a}(t)}{R_{a}(t)}, s_{a}(t)=\lambda \hat{y}_{a}(t)$.

Due to the simplifying assumption of the utility function, the consumption levels are proportional to the disposable income. As the disposable income is related to wealth and current income, our conclusion is similar to the Keynesian consumption function (which is "empirical-friendly") rather than to the presumed constant savings rate in the Solow model (Zhang, 2005, 2008)

According to the definition of $s_{a}(t)$, the wealth accumulation for the rural household is given by

$\bar{k}_{a}(t)=s_{a}(t)-\bar{k}_{a}(t)$.

\section{Equilibrium Conditions for Population Mobility}

For simplicity, we restrict the analysis to the case that all households obtain the same level of utility at any point of time. This also comes out of our assumption that the population is homogeneous and people can change their residential location freely without any transaction costs and time delay. The conditions that households get the same level of utility at any location at each point of time is represented by

$U_{i}\left(\omega_{1}, t\right)=U_{i}\left(\omega_{2}, t\right)=U_{a}(t), 0 \leq \omega_{1}, \omega_{2} \leq \bar{L}_{i}(t)$.

It should be noted that we neglect possible costs for migration. In reality, to change housing location costs. Although the condition of utility equalization is often used in the literature of urban economics, the assumption of utility equalization is rarely used in the literature of economic dynamics as the temporary equilibrium condition of population distribution. In this study, we treat $\bar{L}_{i}$ as an endogenous variable. We assume that conversion of land use between the rural and urban areas is costless and is made without any delay in time. The conversion may be affected by many factors. See, for instance, Carrión-Flores and Irwin (2004), for the contemporary literature of determinants of land conversion.

The labor force employed by the industrial sector is equal to the urban population. That is

$$
\int_{0}^{\bar{L}_{i}(t)} n(\omega, t) d \omega=N_{i}(t) .
$$

As the state is isolated, the total population is distributed over the whole space. The population constraint is given by
$N_{i}(t)+N_{a}(t)=N$.

The total consumption of the industrial goods, $C(t)$, is the sum of the consumption of the urban and rural population

$$
\int_{0}^{\bar{L}_{i}(t)} n(\omega, t) c_{i}(\omega, t) d \omega+c_{a}(t) N_{a}(t)=C(t) .
$$

The output level of the industrial sector is equal to the national consumption of industrial goods and national net saving. That is

$$
C(t)+S(t)-K(t)+\delta_{k} K(t)=F(t),
$$

where $S(t)$ is the total saving of the economy

$$
S(t)=\int_{0}^{\bar{L}_{i}(t)} s_{i}(\omega, t) n(\omega, t) d \omega+s_{a}(t) N_{a}(t) .
$$

The output level of the agricultural sector is equal to the national consumption of agricultural product. That is

$$
\int_{0}^{\bar{L}_{i}(t)} q_{i}(\omega, t) n(\omega, t) d \omega+q_{a}(t) N_{a}(t)=F_{a}(t) .
$$

The assumption that capital is fully employed is given by

$K_{i}(t)+K_{a}(t)=K(t)$.

The total capital stocks employed by the production sectors is equal to the total wealth owned by all the households. That is

$\bar{K}_{i}(t)+\bar{k}_{a}(t) N_{a}(t)=K(\omega, t)$,

where $\bar{K}_{i}(t)$ is the total wealth owned by the urban population, that is

$\bar{K}_{i}(t)=\int_{0}^{\bar{L}_{i}(t)} \bar{k}_{i}(\omega, t) n(\omega, t) d \omega$.

The land is fully used

$\bar{L}_{i}(t)+\bar{L}_{a}(t)=\bar{L}$,

in which

$\bar{L}_{a}(t)=L_{0 a}(t)+L_{a}(t) N_{a}(t)$.

The land rend for the urban and rural use are equal at the boundary between the urban and rural areas (see, Brueckner and Fansler, 1983). That is 


$$
R_{i}\left(L_{i}, t\right)=R_{a}(t)
$$

We have thus built the dynamic growth model with endogenous spatial distribution of wealth, consumption and population, wealth accumulation and residential location. Although the system consists of many equations, the economic mechanisms are few - firms maximize their profits, households maximize their utilities, all the markets are perfect competitive, and all the factors are fully employed.

\section{DETERMINATION OF SPATIAL EQUILIBRIUM}

As dynamic analysis is too complicated, we are concerned with equilibrium. It should be noted that the model is developed as a dynamic one, although the analysis will be focused only on the static state. The static analysis is mainly because it is complicated to analyze behavior of the model. It is meaningful to introduce dynamics because, for instance, the impact of the propensity to save can be properly explained only in a dynamic model. First, we demonstrate a procedure for determining equilibrium values of all the variables.

\section{Lemma 1}

The equilibrium values of all the variables can be determined by the following procedure: $k_{i}$ by $(\mathrm{A} 20) \rightarrow$ $r$ and $w_{i}$ by equations (2) $\rightarrow f_{i}=A_{i} k_{i}^{\alpha_{i}} \rightarrow K$ by equation $(\mathrm{A} 31) \rightarrow \bar{L}_{i}$ by $(\mathrm{A} 25) \rightarrow \bar{k}_{i}(\omega)$ and $\bar{k}_{a}$ by equations $(\mathrm{A} 23) \rightarrow s_{j}=\bar{k}_{j} \rightarrow w_{a}$ by equation (A22) $\rightarrow$ $\bar{r}$ by equation $(\mathrm{A} 17) \rightarrow k_{a}$ by equations $(\mathrm{A} 14) \rightarrow N_{i}$ and $N_{a}$ by equations $(\mathrm{A} 13) \rightarrow K_{j}=k_{j} N_{j}, j=i, a \rightarrow$ $\bar{K}_{j}=\bar{k}_{j} N_{j} \rightarrow n(0)$ by equation $(\mathrm{A} 30) \rightarrow n(\omega)$ by equation $(\mathrm{A} 26) \rightarrow L_{i}(\omega)=1 / n(\omega) \rightarrow R_{a}$ by equation $(\mathrm{A} 24) \rightarrow R_{i}(\omega)=\eta \bar{k}_{i}(\omega) n(\omega) / \lambda \rightarrow L_{a}$ by equation (A3) $\rightarrow \bar{L}_{a}=\bar{L}-\bar{L}_{i} \rightarrow L_{0 a}$ by equation (30) $\rightarrow$ $F_{i}=f_{i} N_{i} \rightarrow F_{a}$ by (3) $\rightarrow p$ by equation $(\mathrm{A} 9) \rightarrow q_{i}(\omega)$, $c_{i}(\omega)$ and $\hat{y}_{i}(\omega)$ by equations $(\mathrm{A} 2) \rightarrow q_{a}, \quad c_{a}$ and $\hat{y}_{a}$ by equations (A3) $\rightarrow C$ and $S$ by equations (A18).

This lemma shows how we can determine the equilibrium values of all the variables. We don't interpret conditions for existence of equilibrium because they are too complicated. We will discuss conditions later on with zero travel cost in the urban area. The system determines the national output, the output levels of the two sectors, the division of labor, the population distribution, consumption structures of the urban and rural households, land rents, the rate of interest, the wage rates of the urban workers and farmers, the price of agricultural goods, and the income from the land ownership. Before simulating the model with specified parameter values, we discuss some relations among the variables with presumed existence of equilibrium.

For convenience of interpretation, we neglect the pecuniary travel cost in the reminder of this study, that is, $\Gamma_{c}=0$. The omission will greatly simplify our interpretations as it makes it possible to explicitly determine the boundary between the urban and rural areas. The distance effects on the urban residential location and urban spatial pattern are reflected by travel time (which is a function of transportation conditions) and time value. It can be seen that we may assume a distance-independent cost function and still explicitly solve the problem as shown below. As far as economic geography is concerned, the omission of transportation costs may not affect the main results of this model, except that the gradients of the residential density curve and land rent may be steeper when transportation costs are taken into account. From equations $(\mathrm{A} 23)$ and $\hat{y}_{i}(\omega)=\bar{k}_{i}(\omega) / \lambda$, we have

$\bar{k}_{i}\left(\omega_{1}\right)=\bar{k}_{i}\left(\omega_{2}\right), \hat{y}_{i}\left(\omega_{1}\right)=\hat{y}_{i}\left(\omega_{2}\right), 0 \leq \omega_{1}, \omega_{2} \leq \bar{L}_{i}$.

The per-capita wealth, $\bar{k}_{i}(\omega)$, and disposable income, $\hat{y}_{i}(\omega)$, are homogenous over the urban area. All urban residents receive the same income and own the same amount of wealth at each point of time. This property results from the assumption that we neglect transportation costs. As shown in the Appendix, if transportation costs are not omitted, the property may not hold.

We specify the travel time function as follows: $\Gamma(\omega)=v \omega$, in which $1 / v$ is the travel speed. In this study, we assume the travel speed is constant. We neglect possible factors, such as change in transportation technology or congestion, which may affect the travel speed. We have

$T_{h}(\omega)=T_{0}-v \omega, 0 \leq \omega \leq \bar{L}_{i}$.

By equations (A25) and (33), we solve the boundary between the urban and rural areas as a unique function of the national capital stock as follows

$$
\begin{aligned}
& \bar{L}_{i}(K)=\frac{T_{0}}{v}-\frac{1}{v} \\
& {\left[\left(\frac{w_{0}}{\alpha_{1} N k_{i}-\left(\alpha_{1}-k_{i}^{\beta_{i}}\right) K}+\bar{\eta}\right)^{1 / \rho} \frac{\theta K^{1 / \rho}}{\left(w_{i}+\bar{\eta} K\right)^{1 / \rho}}\right]^{1 / \sigma} .}
\end{aligned}
$$

where $w_{0}=A_{i} \beta_{a} \alpha_{i} k_{i} / \alpha_{a}$. By equation (A30), we obtain the residential density nearest to the CBD as a function of $K$ as follows 


$$
n(0)=\left(\frac{\lambda}{\eta}\right)\left(\frac{\theta \bar{k}_{a}^{1 / \rho} \Lambda_{a}^{-\eta_{0}}}{T_{0}^{\sigma} \bar{k}_{i}^{1 / \rho-\eta_{0}}}\right)^{1 /\left(a-\eta_{0}\right)},
$$

in which

$$
\Lambda_{a}(K) \equiv \frac{\varsigma \alpha_{i} f_{i} K_{a} / \alpha_{a} k_{i}+\eta \bar{K}_{a} / \lambda}{\bar{L}-\bar{L}_{i}} .
$$

By equations (A31), (34) and (35), we find the equation for determining $K$

$$
\begin{aligned}
& \Omega(K) \equiv\left(1-\frac{k_{i}^{\beta_{i}}}{\alpha_{1}}\right) \frac{K}{k_{i}}+ \\
& \frac{n(0)\left[\left(T_{0}-v \bar{L}_{i}(K)\right)^{1+\sigma / \eta_{0}}-T_{0}^{1+\sigma / \eta_{0}}\right]}{\left(1+\sigma / \eta_{0}\right) v T_{0}^{\sigma / \eta_{0}}}=0 .
\end{aligned}
$$

Although we obtain the equation for determining the national capital, as the expression is tedious it is not easy to interpret its properties. We will solve the equation by simulation.

Before simulating the model, we examine properties of the residential density over space. From equations (A26), the residential distribution is given by

$n(\omega)=n(0)\left(\frac{T_{h}(\omega)}{T_{h}(0)}\right)^{\sigma /\left(\eta_{0}-a\right)}$.

As $T_{h}\left(\omega_{1}\right) / T_{h}\left(\omega_{2}\right)>1$ if $\omega_{1}<\omega_{2}$, we see that if $\eta_{0}-a>0$, then $n\left(\omega_{1}\right)>n\left(\omega_{2}\right)$. The residential density is higher nearer the CBD. As traveling costs more as the residence is further away from the CBD, it is reasonable to observe the declination of the residential density as the distance from the CBD increases. Yet, if $\eta_{0}-a<0$, the residential density distribution is inverse to the case of $\eta_{0}-a>0$ in the sense that the further the residential location is away from the CBD, the higher the density is. To see why this happens, the term becomes negative only when $0<\eta_{0}<a$. A positive $a$ means that as the residential density rises, the local attractiveness as residential area is increased. The condition, $0<\eta_{0}<a$, implies that the individual welfare is positively strongly affected by, for instance, social interactions among local people and the propensity to use land is low. As people highly evaluate interacting with each other among locals, the urban residential density becomes higher further away from the CBD. In this study, we limit our examination to the case of $a=0$, which implies $\eta_{0}-a>0$. We also have $\theta_{i}=\bar{\theta}_{i}$. This assumption is made only for getting an explicit solution of the boundary as a function of the national capital stocks. As we have already shown how to solve the equilibrium in Appendix, as far as simulation is concerned, it is not difficult to study the behavior of the system when the parameter is not zero. Moreover, as the rest of the paper is concerned with the equilibrium and how equilibrium is affected by parameter changes, the requirement of $a=0$ will not affect our main conclusions.

By equation (A6), we have

$$
\frac{R_{i}(\omega)}{R_{i}(0)}=\left(\frac{T_{h}(\omega)}{T_{h}(0)}\right)^{\sigma / \eta_{0}} .
$$

The land rent declines as the residential area is further away from the CBD. By equations (13) and (32), we have

$$
\begin{aligned}
& q_{i}\left(\omega_{1}\right)=q_{i}\left(\omega_{2}\right), c_{i}\left(\omega_{1}\right)= \\
& c_{i}\left(\omega_{2}\right), \frac{L_{i}\left(\omega_{1}\right)}{L_{i}\left(\omega_{2}\right)}=\frac{R_{i}\left(\omega_{2}\right)}{R_{i}\left(\omega_{1}\right)}, s_{i}\left(\omega_{1}\right)=s_{i}\left(\omega_{2}\right) .
\end{aligned}
$$

The consumption levels of agricultural and industrial goods by the urban households are invariant in location. This property holds only in steady state, depending on some special assumptions like the omission of pecuniary travel costs and effects of the residential density on amenity. It not is held even for the general model developed in this paper. Consumption of lot size increases as the residential area is further from the CBD. It should be noted that the total expenditure on housing by per household, $R_{i}(\omega) L_{i}(\omega)$, is invariant in space. That is

$$
R_{i}\left(\omega_{1}\right) L_{i}\left(\omega_{1}\right)=R_{i}\left(\omega_{2}\right) L_{i}\left(\omega_{2}\right) .
$$

As the housing rent declines in location, we see that the housing consumption per household increases as the dwelling site is further away from the CBD.

We now determine equilibrium values of the variables by simulation. We specify parameter values as follows

$$
\begin{aligned}
& A_{i}=1.2, A_{a}=1.1, N=10, L=20, \alpha_{i}=0.3, \\
& \alpha_{a}=0.2, \beta_{a}=0.2, \mu_{0}=0.05, \xi_{0}=0.08, \\
& \eta_{0}=0.07, \lambda_{0}=0.7, \sigma=0.5, \bar{\theta}_{i}=3.1, \\
& \theta_{a}=3, T_{0}=1, v=0.1, \delta_{k}=0.04 .
\end{aligned}
$$

The population is fixed at 10 units and the urban size at 20 units. The total productivities of the industrial and agricultural sectors are respectively equal to 1.2 and 1.1. We specify the parameters, $\alpha_{i}, \alpha_{a}$ and $\beta_{a}$ respectively with $0.3,0.2$ and 0.2 . The propensities to consume agricultural goods, industrial goods and lot 
size are respectively specified at $0.05,0.08$ and 0.07 .

This implies that if the household decides to spend 10,000 dollars on the current consumption, the household spends respectively 2,500, 4,000 and 3,500 dollars on the agricultural goods, industrial goods and housing. The propensity to save is 0.7 . The propensity to use leisure is specified at 0.5 . The specification of $\bar{\theta}_{i}=3.1$ and $\theta_{a}=3$ means that people prefer living in city than in countryside. The depreciation rate is specified at 0.04 . It should be remarked that although the specified values are not based on empirical observations, the choice does not seem to be unrealistic. For instance, some empirical studies on the US economy demonstrate that the value of the parameter, $\alpha$, in the Cobb-Douglas production is approximately equal to 0.3 (for instance, Abel and Bernanke, 1998). With regard to the technological parameters, what are important in our study are their relative values. This is similarly true for the specified differences in land and amenity parameters.

We follow the procedure described in proving Lemma 1 to identify equilibrium solutions. Here, we use equations (32)-(37) for the corresponding variables. First, by equation (37), we solve $K$ as in Figure 2. The equation has multiple solutions. We show only two of them. It can be shown that the equation has a unique meaningful solution of

$K=134.350$.

Although as shown in Figure 1b, $K=303.056$ satisfies the equation, the solution is meaningless as at this point the labor force employed by the agricultural sector is negative and $L_{i}>L_{0}$.

Following the procedure described in proving Lemma 1, we calculate the equilibrium values of the location-independent variables, with $K=134.350$, as follows:

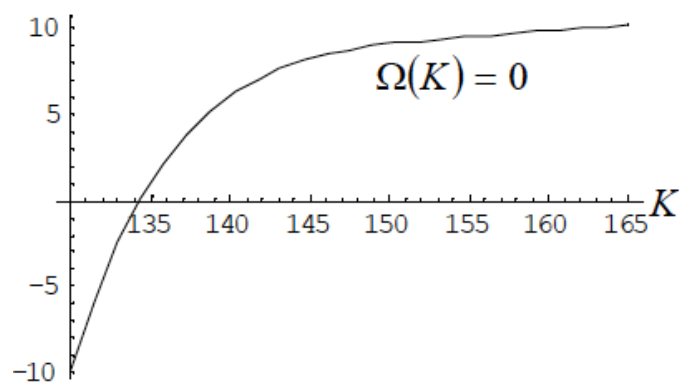

(a) the unique meaningful solution

$$
\begin{aligned}
& K=134.35, r=0.021, p=0.876, w_{i}=1.803, \\
& w_{a}=0.983, R_{a}=0.494, K_{i}=102.663, \\
& K_{a}=31.686, N_{i}=8.047, \quad N_{a}=1.953, L_{0 a}=11.728, \\
& F_{i}=20.728, F_{a}=10.957, f_{i}=2.576, \\
& f_{a}=5.611, k_{i}=12.757, \quad k_{a}=16.227, \\
& l_{a}=5.970, \hat{y}_{i}=18.050, \bar{k}_{i}=14.039, q_{i}=1.145, \\
& c_{i}=1.605, \hat{y}_{a}=14.073, \bar{k}_{a}=10.956, \\
& q_{a}=0.893, c_{a}=1.251, L_{a}=2.216, \hat{K}_{i}=112.976, \\
& \hat{K}_{a}=21.373, \bar{r}=1.919, \bar{L}_{i}=4.017, \bar{L}_{a}=15.984 .
\end{aligned}
$$

As the lot size, land rent and residential density are dependent on the distance from the CBD, we represent them in plot. Figure 3 illustrates how these variables vary in distance, $0 \leq \omega \leq \bar{L}_{i}$.

We see that the urban wage rate is much higher than the rural wage rate. It should be noted that this difference in wage rates between the two professions is neither due to difference in human capital as in the new economic geography nor due to possibility of unemployment in city as in the Todaro-Harris model. The wage difference between the two areas for the same worker results from amenity differences between the urban and rural areas and transport conditions. Another factor for explaining the difference is that the difference offsets commuting costs. We see that with the specified parameter values, the economy is highly urbanized. The share of the urban population is 80.5 percent and the share of the rural population is 19.5 percent. Most of the population lives in the city. The value of the rural output $p F_{a}$, is less than half of the value of the industrial sector, $F_{i}$. The share of the urban land in the total land is 20 percent and the rural land is 80 percent. Among the rural land use of 15.98 units, 11.73 units is devoted to the agricultural production. The urban household consumes more the agricultural and industrial goods than the rural

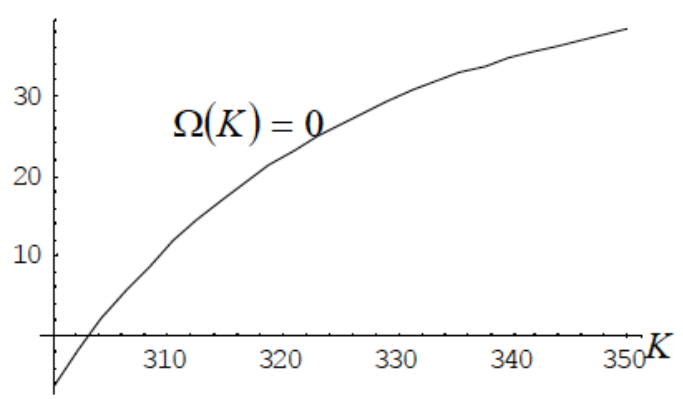

(b) a meaningless solution

Figure 2: Possible Solutions of Equation (36). 


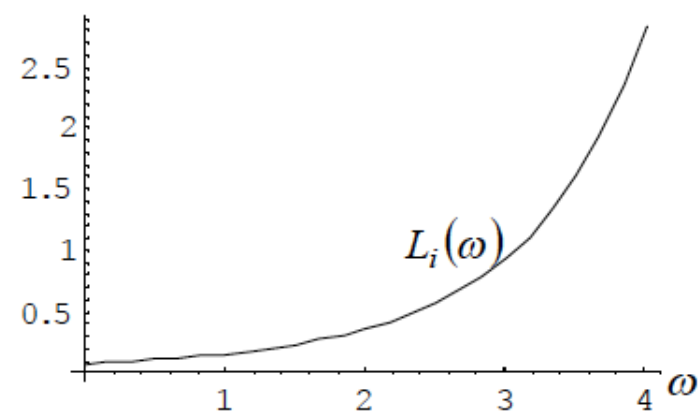

Figure 3: Lot Size, Land Rent and Residential Density in the City.

household, but the urban household pays higher rent and live in smaller space than the rural household. Moreover, the urban residents spend time on travel. It should be remarked that the differences in the living conditions between the rural and urban residents results from the assumption that the population is homogenous. This implies that if the urban lifestyle has some comparative advances, then the rural lifestyle should also have some advances because the utility level from the two lifestyles is equal. A more realistic approach is to take account of differences in the population. One well-accepted approach in spatial economics is to classify the population into skilled and unskilled. Under certain conditions, all skilled workers are employed in the city and the unskilled both by the city and the countryside. As far as urban economic geography is concerned, the prediction of the model is the same as the standard Alonso model. Nevertheless, our model shows how the urban economic geography is connected with the rest of the national economy. The advantage of our approach over the traditional models, like the Solow model and the Alonso model, becomes evident in the following comparative statics analysis.

\section{COMPARATIVE STATIC ANALYSIS}

This section studies effects of changes in some parameters on the economic structure and geography. As the system has a unique equilibrium, we can make comparative static analysis.

\subsection{An Improvement in the Total Factor Productivity of the Industrial Sector}

First, we examine the case that all the parameters, except the productivity of the industrial sector, $A_{i}$, are the same as in (38). We increase the productivity level, $A_{i}$, from 1.2 to 1.3 . The simulation results are summarized in (40)

$\bar{\Delta} K=12.11, \bar{\Delta} r=0, \bar{\Delta} p=9.58, \bar{\Delta} w_{i}=12.11$, $\bar{\Delta} w_{a}=11.11, \bar{\Delta} R_{a}=12.11, \bar{\Delta} K_{i}=12.11$,

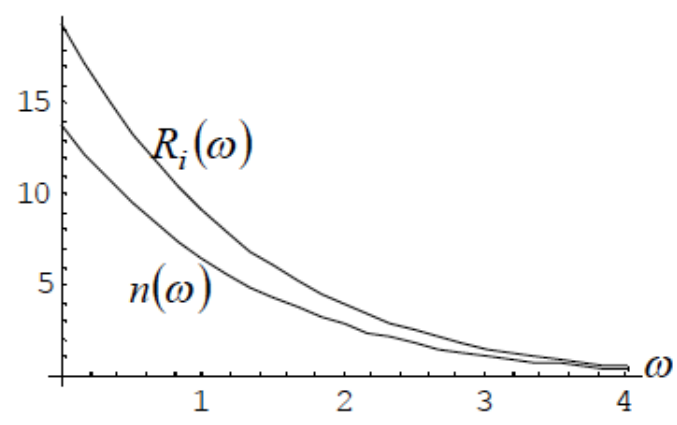

$\bar{\Delta} K_{a}=12.11, \bar{\Delta} N_{i}=0, \bar{\Delta} N_{a}=0, \bar{\Delta} L_{0 a}=0$,

$\bar{\Delta} F_{i}=12.11, \bar{\Delta} F_{a}=2.31, \bar{\Delta} f_{i}=12.11$,

$\bar{\Delta} f_{a}=2.31, \bar{\Delta} k_{i}=12.11, \bar{\Delta} k_{a}=12.11$,

$\bar{\Delta} l_{a}=0, \bar{\Delta} \hat{y}_{i}=12.11, \bar{\Delta} \bar{k}_{i}=12.11, \bar{\Delta} q_{i}=2.31$,

$\bar{\Delta} c_{i}=12.11, \bar{\Delta} \hat{y}_{a}=12.11, \bar{\Delta} \bar{k}_{a}=12.11$,

$\bar{\Delta} q_{a}=2.31, \bar{\Delta} c_{a}=12.11, \bar{\Delta} L_{a}=0, \bar{\Delta} \bar{K}_{i}=12.11$,

$\bar{\Delta} \bar{K}_{a}=12.11, \bar{\Delta} \bar{r}=12.11, \bar{\Delta} \bar{L}_{i}=0, \bar{\Delta} \bar{L}_{a}=0$.

Here, a variable $\bar{\Delta} x_{j}$ stand for the change rate of the equilibrium value of the variable $x_{j}$ in percentage due to the change in the parameter value from $A_{i 0}$ (=1.2 in this case) to $A_{i 1}(=1.3)$. That is

$\bar{\Delta} x_{j} \equiv \frac{x_{j}\left(A_{i 1}\right)-x_{j}\left(A_{i 0}\right)}{x_{j}\left(A_{i 0}\right)} \times 100$,

where $x_{j}\left(A_{i 1}\right)$ stands for the equilibrium value of the variable $x_{j}$ with the parameter value $A_{i 1}$ and $x_{j}\left(A_{i 0}\right)$ stands for the value of the variable $x_{j}$ with the parameter value $A_{i 0}$. We will use the symbol $\bar{\Delta}$ with the same meaning when we analyze other parameters. The effects on the distance-dependent variables are given as follows

$$
\bar{\Delta} n(\omega)=0, \bar{\Delta} R_{i}(\omega)=12.11,0 \leq \omega \leq \bar{L}_{i}^{*} .
$$

It should be noted that the value of $\bar{L}_{i}^{*}$ is the lower value of the boundaries before and after the change, that is, $\bar{L}_{i}^{*}=\min \left\{\bar{L}_{i}\left(A_{i 0}\right), \bar{L}_{i}\left(A_{i 1}\right)\right\}$. We will use $\bar{L}_{i}^{*}$ to refer to the lower value of the boundaries in the remaining study when discussing the urban residential density and land rent.

As the productivity of the industrial sector is increased, the total capital stock, $K$, the output level of 
the industrial sector, $F_{i}$, and the output level of the agricultural sector, $F_{a}$, are increased. The capital stocks employed by the two sectors, $K_{a}$ and $K_{i}$, are increased. The labor distribution between the two sectors, $N_{i}$ and $N_{a}$, and the rate of interest, $r$, are not affected by the change of the productivity. The urban boundary, $\bar{L}_{i}$, is not affected. The land use distribution, $\bar{L}_{i}$ and $L_{0 a}$, is not affected by the productivity change. We see that the increase in the industrial sector's output level is due to the increase in the productivity and the increase in the capital stocks employed by the sector, and the increase in the agricultural sector's output level is due to the increase in the increase in the capital stocks employed by the sector. The price of the agricultural goods $p$, is increased as the productivity of the industrial sector is improved. The wage rates in the two sectors, $w_{a}$ and $w_{i}$, are increased. The lot sizes of the worker and farmer, $L_{i}(\omega)$ and $L_{a}$, are not affected. The land rents in the urban and rural areas, $R_{i}(\omega)$ and $R_{a}$, are increased. The consumption levels of the agricultural and industrial goods both by the urban and rural residents, $q_{i}(\omega), c_{i}(\omega), q_{a}$ and $c_{a}$, are increased. As the production technology of the city is improved, the urban output will be improved and the wage will be increased initially when the system achieves the new equilibrium. As the urban wage rate rises, some farmers will move to the city with all the other conditions being the same. As the amenities are fixed, more urban workers will lead to a rise in urban rent or/and a reduction of the rural area. As the urban area becomes less attractive as a residential area, the rural area becomes more attractive. On the other hand, as capital is increased, the rural sector employs more capital and the rural wage rate and agricultural price are increased. Under the specified technological change, the population distribution and urban boundary are actually not affected. Although the land rents and the price of the agricultural good are increased at the new equilibrium point, the real variables are either improved or not affected by the technological change. It should be noted that as the system involves many variables and different economic forces, it is quite tedious to verbally explain how changes in a parameter affects the entire system.

\subsection{A Rise in Amenity Level}

We now examine effects of changes in the amenity levels. First, we note that the urban and rural amenities, $\theta_{i}$ and $\theta_{a}$, affect the equilibrium only through equation (37). Moreover, it is not their values but the value of their ratio, $\theta_{i} / \theta_{a}$, that affects the system. It is sufficient for us to examine one of the two parameters. We specify the amenity change as follows: $\theta_{i}: 3.1 \Rightarrow 3.2$. The effects upon the distanceindependent variables are summarized as follows

$$
\begin{aligned}
& \bar{\Delta} K=14.04, \bar{\Delta} r=0, \bar{\Delta} p=11.94, \\
& \bar{\Delta} w_{i}=12.11, \bar{\Delta} w_{a}=22.73, \bar{\Delta} R_{a}=12.71, \bar{\Delta} K_{i}=14.04, \\
& \bar{\Delta} K_{a}=1404, \bar{\Delta} N_{i}=1.72, \bar{\Delta} N_{a}=-7.08, \\
& \bar{\Delta} L_{0 a}=1.18, \bar{\Delta} F_{i}=14.04, \bar{\Delta} F_{a}=1.88, \\
& \bar{\Delta} f_{i}=12.11, \bar{\Delta} f_{a}=9.64, \bar{\Delta} k_{i}=12.11, \\
& \bar{\Delta} k_{a}=22.73, \bar{\Delta} l_{a}=8.89, \bar{\Delta} \hat{y}_{i}=13.11, \bar{\Delta} \bar{k}_{i}=13.11, \\
& \bar{\Delta} q_{i}=1.04, \bar{\Delta} c_{i}=13.11, \bar{\Delta} \hat{y}_{a}=16.99, \\
& \bar{\Delta} \bar{k}_{a}=16.99, \bar{\Delta} q_{a}=4.51, \bar{\Delta} c_{a}=16.99, \bar{\Delta} L_{a}=3.79 \\
& \bar{\Delta} \bar{K}_{i}=15.05, \bar{\Delta} \bar{K}_{a}=8.70, \bar{\Delta} \bar{r}=14.04, \\
& \bar{\Delta} \bar{L}_{i}=0.42, \bar{\Delta} \bar{L}_{a}=-0.11 .
\end{aligned}
$$

The effects on the distance-dependent variables are given as follows

$$
\begin{aligned}
& \bar{\Delta} n(\omega)=1.68, \bar{\Delta} L_{i}(\omega)=-1.66, \\
& \bar{\Delta} R_{i}(\omega)=15.01,0 \leq \omega \leq \bar{L}_{i}^{*} .
\end{aligned}
$$

As the urban amenity level is improved (or as the rural amenity level is reduced), the total capital stock, $K$, the output level of the industrial sector, $F_{i}$, and the output level of the agricultural sector, $F_{a}$, the capital stocks employed by the two sectors, $K_{a}$ and $K_{i}$, are increased. The increase in the urban amenity attracts more people from the rural area to the urban area. That is, the urban population, $N_{i}$, is increased and the rural population, $N_{a}$, is reduced. The boundary, $\bar{L}_{i}$, moves further away from the CBD. The urban land, $\bar{L}_{i}$, is increased and the rural land, $\bar{L}_{a}$, is reduced. The land for agricultural production, $L_{0 a}$, is reduced. The lot size in the city, $L_{i}(\omega)$, is reduced and the lot size in the countryside, $L_{a}$, is increased. The rate of interest, $r$, is not affected. The price of agricultural goods, $p$, is increased. The wage rates of the two sectors, $w_{i}$ and $w_{a}$, and the land rent in the city and countryside, $R_{a}$ and $R_{i}(\omega)$, are increased. The urban residential density, $n(\omega)$, and the rent income from the land, $\bar{r}$, are increased. The capital intensities of the two sectors, $k_{i}$ and $k_{a}$, and per worker output levels of the two sectors, $f_{i}$ and $f_{a}$, are increased. The consumption levels of the agricultural and industrial goods both by the urban and rural residents, 
$q_{i}(\omega), c_{i}(\omega), \quad q_{a}$ and $c_{a}$, are increased. The per capita wealth levels of the urban and rural areas, $\bar{k}_{i}$ and $\bar{k}_{a}$, are increased. Our simulation results show that under the given technological conditions and preference, an improvement in the rural living conditions amenity will reduce economic growth. That is, if the economic production is not characterized of constant returns to scale, the national economy may worse off if the government improves, for instance, the rural infrastructures. It should be noted that we have this counterintuitive conclusion as we assume that the infrastructure improvement has no effect on the productivity of the rural economy (only on the utility of rural workers).

A rise in the urban amenity increases the city's attractiveness for residential dwelling. For the given wage rate and other conditions, some farmers will like to migrate to the city. As the city has more labor force, its total output tends to rise. If the capital is not changed, the urban wage rate tends to fall. Nevertheless, as the total industrial output rises, the economy saves more and the total capital stock is increased. As farmers migrate to the city where the technology is more advanced than the agricultural sector, the shift of some labor force from the urban area to the rural area also increases the national output level (with the agricultural price being constant). As the relative output of the agricultural product tends to fall and the total income tends to rise, the price of the agricultural product tends to rise. As more people live in the city, the urban land rent tends to rise. Although less people live in the rural area, the rural land rent still rises (because the other two opposite forces work in the system: the price of the agricultural product is increased and the amount of land available for the rural use is reduced). As each sector's output and capital stock are increased, the wage rates of the two sectors are increased. As some farmers move from the rural area to the city, the rural area's wage rate is increased more than in the city in terms of percentage.

\subsection{A Shortening in the Travel Time to the CBD}

Another important factor for economic growth is transportation conditions. In our model, the transportation system is exogenous. The main parameter is the travel speed, $1 / v$. We now consider effects of an increase in the travel speed to the CBD upon the system. We specify the change as follows: $v: 0.1 \Rightarrow 0.09$. The urban households spend less time on travel from a given location. We summarize the effects on the distance-independent variables as

$$
\begin{gathered}
\bar{\Delta} K=0.48, \bar{\Delta} r=0, \bar{\Delta} p=1.86, \bar{\Delta} w_{i}=0, \\
\bar{\Delta} w_{a}=2.53, \bar{\Delta} R_{a}=2.27, \bar{\Delta} K_{i}=0.48,
\end{gathered}
$$

$$
\begin{aligned}
& \bar{\Delta} K_{a}=0.48, \bar{\Delta} N_{i}=0.48, \bar{\Delta} N_{a}=-1.99, \\
& \bar{\Delta} L_{0 a}=-1.75, \bar{\Delta} F_{i}=0.48, \bar{\Delta} F_{a}=-1.35, \\
& \bar{\Delta} f_{i}=0, \bar{\Delta} f_{a}=0.65, \bar{\Delta} k_{i}=0, \bar{\Delta} k_{a}=2.53 \\
& \bar{\Delta} l_{a}=0.25, \bar{\Delta} \hat{y}_{i}=0.25, \bar{\Delta} \bar{k}_{i}=0.25, \\
& \bar{\Delta} c_{i}=, \bar{\Delta} \hat{y}_{a}=, \bar{\Delta} \hat{k}_{a}=, \bar{\Delta} q_{a}=, \bar{\Delta} c_{a}=, \bar{\Delta} L_{a}=, \bar{\Delta} \hat{K}_{i}=, \\
& \bar{\Delta} \bar{K}_{i}=0.73, \bar{\Delta} \bar{K}_{a}=-0.84, \bar{\Delta} \bar{r}=0.48, \\
& \bar{\Delta} \bar{L}_{i}=8.35, \bar{\Delta} \bar{L}_{a}=-2.10 .
\end{aligned}
$$

The urban boundary moves further from 4.02 to 4.36. As the change ratios of the distance-dependent variables are dependent on location, we present the results in Figure 4, in which we have: $0 \leq \omega \leq \bar{L}_{i}^{*}$.

From Figure 4, we see that an improvement in the transportation conditions increases the urban lot size near the $C B D$ and reduces the lot size far away from the CBD. This also means that the urban residential density is reduced near the CBD and is increased far away from the CBD. The urban spatial configuration becomes platter as travel speed is increased. It should be remarked that this study neglects other important relations between economic growth and transportation conditions. For instance, it is important to take account of infrastructure costs. If work time is endogenous, effects on the spatial configuration and national economic growth should be different from the current model. The urban land rent is reduced near the CBD but increased far away from the CBD.

From (44), we see that as the transportation conditions are improved, the total capital stock, $K$, the output level of and the labor force and capital stocks employed by the industrial sector, $F_{i}$ and $K_{i}$, are increased. The output level of, and the labor force, land and capital stocks employed by the agricultural sector, $F_{a}, \quad N_{a}, K_{a}$, and $L_{0 a}$, are reduced. The rate of interest and the urban wage rate, $r$ and $w_{i}$, are not affected. The price of agricultural goods and the rural wage rate, $p$ and $w_{a}$, are increased. The land rent in the countryside, $R_{a}$, is increased. The total rent income from the land, is increased. The lot size in the countryside $L_{a}$, is reduced. The capital intensity and per worker output level of the industrial sector, $k_{i}$ and $f_{i}$, are not affected. The capital intensity, land intensity, and per worker output level of the agricultural sector, $k_{a}, l_{a}$ and $f_{a}$, are increased. The per capita wealth levels of the urban and rural workers, $\bar{k}_{i}$ and $\bar{k}_{a}$, are increased. The consumption levels of the agricultural goods both by the urban and rural 

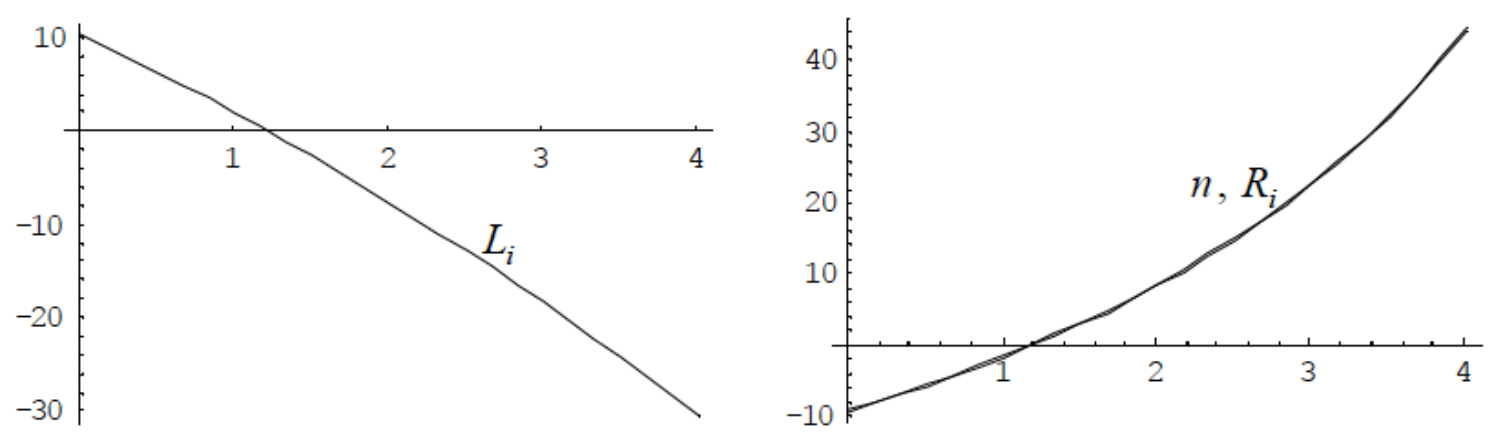

Figure 4: The Effects of an Improvement in Transportation Conditions.

residents, $q_{i}$ and $q_{a}$, are reduced. This occurs as the price of agricultural goods is increased and the land use by the agricultural sector is reduced. The consumption levels of the industrial goods both by the urban and rural residents, $c_{a}$ and $c_{a}$, are augmented.

\subsection{A Rise in the Propensity to Save}

Preference changes, such as the propensity to save and the propensity to consume housing, are well observed but seldom introduced into economic growth theory. We now examine effects of changes in the preference on the economic structure. We now increase the propensity to save as follows: $\lambda_{0}: 0.7 \Rightarrow 0.75$. The simulation results are summarized as follows:

$$
\begin{aligned}
& \bar{\Delta} K=9.04, \bar{\Delta} r=-15.74, \bar{\Delta} p=0.60, \\
& \bar{\Delta} w_{i}=2.38, \bar{\Delta} w_{a}=7.29, \bar{\Delta} R_{a}=0.48, \bar{\Delta} K_{i}=9.51, \\
& \bar{\Delta} K_{a}=7.52, \bar{\Delta} N_{i}=1.25, \bar{\Delta} N_{a}=-5.14, \\
& \bar{\Delta} L_{0 a}=1.27, \bar{\Delta} F_{i}=3.66, \bar{\Delta} F_{a}=1.17, \bar{\Delta} f_{i}=2.38, \\
& \bar{\Delta} f_{a}=6.65, \bar{\Delta} k_{i}=8.17, \bar{\Delta} k_{a}=13.35, \\
& \bar{\Delta} l_{a}=6.67, \bar{\Delta} \hat{y}_{i}=6.93, \bar{\Delta} \bar{k}_{i}=8.54, \bar{\Delta} q_{i}=0.70, \\
& \bar{\Delta} c_{i}=1.31, \bar{\Delta} \hat{y}_{a}=8.58, \bar{\Delta} \bar{k}_{a}=10.21, \bar{\Delta} q_{a}=2.25, \\
& \bar{\Delta} c_{a}=2.87, \bar{\Delta} L_{a}=2.37, \bar{\Delta} \bar{K}_{i}=9.89, \\
& \bar{\Delta} \bar{K}_{a}=4.55, \bar{\Delta} \bar{r}=1.77, \bar{\Delta} \bar{L}_{i}=-0.62, \bar{\Delta} \bar{L}_{a}=0.16 . \\
& \bar{\Delta} n(\omega)=3.86, \bar{\Delta} L_{i}(\omega)=-2.45, \\
& \bar{\Delta} R_{i}(\omega)=-3.72,0 \leq \omega \leq \bar{L}_{i}^{*} .
\end{aligned}
$$

As the propensity to save is increased, the total capital stock, $K$, the output level of the industrial sector, $F_{i}$, and the output level of the agricultural sector, $F_{a}$, the capital stocks employed by the two sectors, $K_{a}$ and $K_{i}$, are increased. It should be remarked that this result is explained by the Solow model as well. Nevertheless, the Solow growth model does not provide further information about other aspects of the economic system. The increase in the propensity to save attracts more people from the rural area to the urban area. The boundary, $\bar{L}_{i}$, moves nearer to from the CBD. This means that the urban land use is reduced. The rural land, $\bar{L}_{a}$, is reduced. The land for agricultural production, $L_{0 a}$, is increased. The lot size in the city, $L_{i}(\omega)$, is reduced and the lot size in the countryside, $L_{a}$, is increased. The rate of interest, $r$, is reduced. The price of agricultural goods, $p$, is increased. The wage rates of the two sectors, $w_{i}$ and $w_{a}$, are increased. The land rent in the city, $R_{i}(\omega)$, is reduced and countryside, $R_{a}$, is increased. The urban residential density, $n(\omega)$, and the rent income from the land, $\bar{r}$, are increased. The capital intensities of the two sectors, $k_{i}$ and $k_{a}$, and per worker output levels of the two sectors, $f_{i}$ and $f_{a}$, are increased. The consumption levels of the agricultural and industrial goods both by the urban and rural residents, $q_{i}(\omega), c_{i}(\omega), q_{a}$ and $c_{a}$, are increased. The per capita wealth levels of the urban and rural areas, $\bar{k}_{i}$ and $\bar{k}_{a}$, are increased.

Possible effects of saving behavior on the economic geography are not well addressed in the literature of theoretical economics. The main reason is that traditional analytical frameworks cannot effectively analyze economic geography with capital accumulation. As our model treats wealth accumulation as endogenous, a shift in the propensity to save should affect the amount of capital and output level of the national economy. As the propensity to save is increased, wealth is increased and rate of interest is reduced. As capital is increased and total output is increased, the wage rates of the two sectors are increased. As labor migrates from the rural to the urban area, the wage rate of the rural area rises more than the urban area in terms of percentage. In association 
with rising of the urban population, the urban residential density is increased and the urban area is extended.

\subsection{A Rise in the Propensity to Consume Housing}

We now increase the propensity to consume the lot size as follows: $\eta_{0}: 0.07 \Rightarrow 0.075$. The effects on the distance-independent variables are summarized as follows:

$\bar{\Delta} K=-1.23, \bar{\Delta} r=0, \bar{\Delta} p=0.50, \bar{\Delta} w_{i}=0$,

$\bar{\Delta} w_{a}=-6.01, \bar{\Delta} R_{a}=2.94, \bar{\Delta} K_{i}=-1.23$,

$\bar{\Delta} K_{a}=-1.23, \bar{\Delta} N_{i}=-1.23, \bar{\Delta} N_{a}=5.08$,

$\bar{\Delta} L_{0 a}=-4.06, \bar{\Delta} F_{i}=-1.23, \bar{\Delta} F_{a}=-1.73$,

$\bar{\Delta} f_{i}=0, \bar{\Delta} f_{a}=-6.48, \bar{\Delta} k_{i}=0, \bar{\Delta} k_{a}=-6.01$,

$\bar{\Delta} l_{a}=-8.69, \bar{\Delta} \hat{y}_{i}=-0.21, \bar{\Delta} \bar{k}_{i}=-0.76$,

$\bar{\Delta} q_{i}=-1.26, \bar{\Delta} c_{i}=-0.76, \bar{\Delta} \hat{y}_{a}=-1.68$,

$\bar{\Delta} \bar{k}_{a}=-2.22, \bar{\Delta} q_{a}=-2.71, \bar{\Delta} c_{a}=-2.22$,

$\bar{\Delta} L_{a}=1.77, \bar{\Delta} \bar{K}_{i}=-1.99, \bar{\Delta} \bar{K}_{a}=2.75$,

$\bar{\Delta} \bar{r}=3.71, \bar{\Delta} \bar{L}_{i}=4.29, \bar{\Delta} \bar{L}_{a}=-1.08$.

The effects on the distance-dependent variables for $0 \leq \omega \leq \vec{L}_{i}^{*}$ are plotted in Figure $\mathbf{5}$.

From Figure 5, we see that an improvement in propensity to consume lot size increases the urban lot size near the CBD and reduces the lot size far away from the CBD. This also means that the urban residential density is reduced near the $C B D$ and is increased far away from the CBD. The urban spatial configuration becomes platter as travel speed is increased. The urban land rent is reduced near the CBD but increased far away from the CBD.

From (47), the total capital stock, $K$, the output level of and the labor force and capital stocks employed by the industrial sector, $F_{i}$ and $K_{i}$, are reduced. The output level of, and the land and capital stocks employed by the agricultural sector, $F_{a}, K_{a}$, and $L_{0 a}$, are reduced, and the labor force, $N_{a}$, is increased. The rate of interest and the urban wage rate, $r$ and $w_{i}$, are not affected. The price of agricultural goods, $p$, is increased and the rural wage rate, $w_{a}$, reduced increased. The land rent in the countryside, $R_{a}$, is increased. The total rent income from the land is not affected. The lot size in the countryside, $L_{a}$, is increased. The capital intensity and per worker output level of the industrial sector, $k_{i}$ and $f_{i}$, are not affected. The capital intensity, land intensity, and per worker output level of the agricultural sector, $k_{a}, l_{a}$ and $f_{a}$, are reduced. The per capita wealth levels of the urban and rural areas, $\bar{k}_{i}$ and $\bar{k}_{a}$, are reduced. The consumption levels of the agricultural goods both by the urban and rural residents, $q_{i}$ and $q_{a}$, are increased. The consumption levels of the industrial goods both by the urban and rural residents, $c_{a}$ and $c_{a}$, are reduced. It should be made clear that the propensity to consume housing refers to urban land only. This explains partly why agricultural good consumption increases, while industrial good consumption decreases.

\subsection{A Rise in the Propensity to Use Leisure Time}

We now increase the propensity to use leisure time as follows: $\sigma: 0.5 \Rightarrow 0.55$. The effects on the distanceindependent variables are summarized as follows:

$$
\begin{aligned}
& \bar{\Delta} K=-0.07, \bar{\Delta} r=0, \bar{\Delta} p=-1.09, \bar{\Delta} w_{i}=0, \\
& \bar{\Delta} w_{a}=-0.35, \bar{\Delta} R_{a}=-1.70, \bar{\Delta} K_{i}=-0.07, \\
& \bar{\Delta} K_{a}=-0.07, \bar{\Delta} N_{i}=-0.07, \bar{\Delta} N_{a}=0.28, \\
& \bar{\Delta} L_{0 a}=1.66, \bar{\Delta} F_{i}=-0.07, \bar{\Delta} F_{a}=1.03, \bar{\Delta} f_{i}=0, \\
& \bar{\Delta} f_{a}=0.75, \bar{\Delta} k_{i}=0, \bar{\Delta} k_{a}=-0.35, \\
& \bar{\Delta} l_{a}=1.37, \bar{\Delta} \hat{y}_{i}=-0.04, \bar{\Delta} \bar{k}_{i}=-0.04, \bar{\Delta} q_{i}=1.07,
\end{aligned}
$$
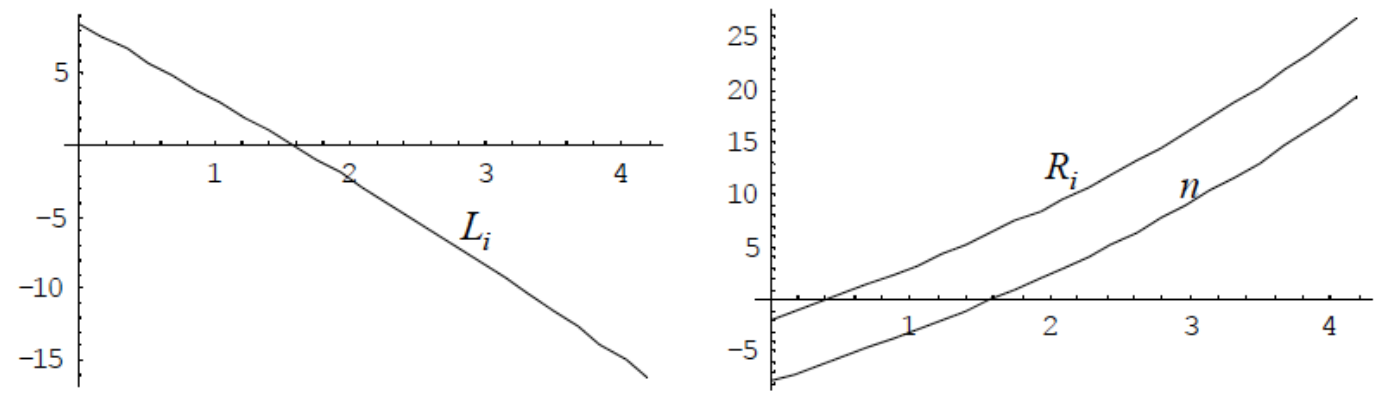

Figure 5: The Effects of a Rise in the Propensity to Consume Housing. 


$$
\begin{aligned}
& \bar{\Delta} c_{i}=-0.04, \bar{\Delta} \hat{y}_{a}=-0.16, \bar{\Delta} \bar{k}_{a}=-0.16, \\
& \bar{\Delta} q_{a}=0.94, \bar{\Delta} c_{a}=-0.16, \bar{\Delta} L_{a}=1.56, \\
& \bar{\Delta} \bar{K}_{i}=-0.10, \bar{\Delta} \bar{K}_{a}=0.12, \bar{\Delta} \bar{r}=-0.07, \\
& \bar{\Delta} \bar{L}_{i}=-6.79, \bar{\Delta} \bar{L}_{a}=1.71 .
\end{aligned}
$$

The total capital stocks and the output level of the industrial sector are reduced and the output level of the agricultural sector is reduced. As the leisure time becomes more preferred, the urban area is reduced. The effects on the distance-dependent variables for $0 \leq \omega \leq \vec{L}_{i}^{*}$ are plotted in Figure 6.

From Figure 6, we see that an increase in the propensity to use leisure time increases the urban lot size The urban land rent is reduced in the city.

\subsection{A Rise in the Propensity to Consume Agricultural Goods}

We now increase the propensity to consume agricultural goods as follows: $\mu_{0}: 0.05 \Rightarrow 0.06$. The effects on the distance-independent variables are summarized as follows:

$$
\begin{aligned}
& \bar{\Delta} K=-4.80, \bar{\Delta} r=13.89, \bar{\Delta} p=8.23, \bar{\Delta} w_{i}=-1.96, \\
& \bar{\Delta} w_{a}=2.02, \bar{\Delta} R_{a}=11.6, \bar{\Delta} K_{i}=-9.09, \\
& \bar{\Delta} K_{a}=9.09, \bar{\Delta} N_{i}=-2.91, \bar{\Delta} N_{a}=11.97, \\
& \bar{\Delta} L_{0 a}=2.36, \bar{\Delta} F_{i}=-4.80, \bar{\Delta} F_{a}=5.55, \\
& \bar{\Delta} f_{i}=-1.96, \bar{\Delta} f_{a}=-5.74, \bar{\Delta} k_{i}=-6.37, \\
& \bar{\Delta} k_{a}=-2.58, \bar{\Delta} l_{a}=-8.58, \bar{\Delta} \hat{y}_{i}=-3.53, \\
& \bar{\Delta} \bar{k}_{i}=-4.59, \bar{\Delta} q_{i}=5.79, \bar{\Delta} c_{i}=-4.59, \\
& \bar{\Delta} \hat{y}_{a}=-1.82, \bar{\Delta} \bar{k}_{a}=-2.90, \bar{\Delta} q_{a}=7.66, \\
& \bar{\Delta} c_{a}=-2.90, \bar{\Delta} L_{a}=-12.99, \bar{\Delta} \bar{K}_{i}=-7.36, \\
& \bar{\Delta} \bar{K}_{a}=8.73, \bar{\Delta} \bar{r}=0.91, \bar{\Delta} \bar{L}_{i}=-4.08, \\
& \bar{\Delta} \bar{L}_{a}=1.02 .
\end{aligned}
$$

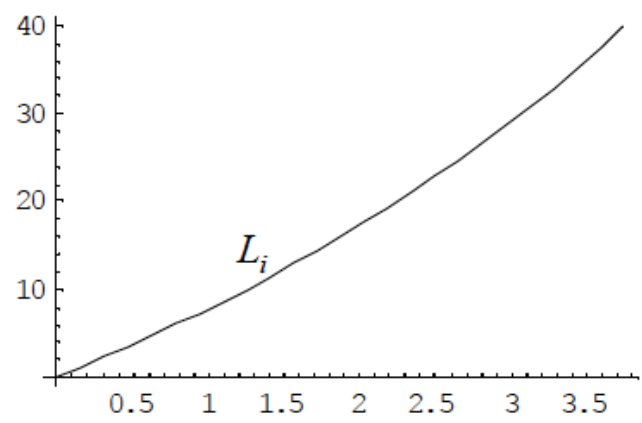

$$
\begin{aligned}
& \bar{\Delta} n(\omega)=-3.54, \bar{\Delta} L_{i}(\omega)=3.67, \\
& \bar{\Delta} R_{i}(\omega)=-7.97,0 \leq \omega \leq \bar{L}_{i}^{*} .
\end{aligned}
$$

As the propensity to consume agricultural goods is increased, the boundary between the urban and rural areas moves nearer the CBD. That is, the urban area is reduced as the population increases its preference for agricultural goods. The total capital stock, $K$, the output level of and the labor force and capital stocks employed by the industrial sector, $F_{i}$ and $K_{i}$, are reduced. The output level of, and the labor force, land and capital stocks employed by the agricultural sector, $F_{a}, N_{a}, K_{a}$, and $L_{0 a}$, are increased. The rate of interest, the price of agricultural goods and the rural wage rate, $r, p$ and $w_{a}$, are increased. The urban wage rate, $w_{i}$, is reduced. The land rent in the countryside, $R_{a}$, is increased. The total rent income from the land, $\bar{r}$, is increased. The lot size in the countryside, $L_{a}$, is reduced. The capital intensity and per worker output level of the industrial sector, $k_{i}$ and $f_{i}$, are reduced. The capital intensity, land intensity, and per worker output level of the agricultural sector, $k_{a}, l_{a}$ and $f_{a}$, are reduced. The per capita wealth levels of the urban and rural areas, $\bar{k}_{i}$ and $\bar{k}_{a}$, are reduced. The consumption levels of the agricultural goods both by the urban and rural residents, $q_{i}$ and $q_{a}$, are increased. The consumption levels of the industrial goods both by the urban and rural residents, $c_{a}$ and $c_{a}$, are reduced.

We also simulated the effects of an increase in the population, specified by $N: 10 \Rightarrow 10.5$. We don't represent the results as they provide few new insights. An increase in the population increases $K, K_{i}$, $K_{a}, N_{i}, N_{a}, F_{i}, F_{a}, n, p, R_{i}, R_{a}$, reduces $l_{a}, f_{a}$, $q_{i}, q_{a}, L_{i}(\omega), L_{a}$, and does not affect the other variables. By simulation, we also show that an increase in the territory (specified as $L: 20 \Rightarrow 21$ ) increases $N_{a}$, $L_{0 a}, \quad F_{a}, l_{a}, f_{a}, q_{i}, q_{a}, L_{a}, L_{i}(\omega), \bar{L}_{i}$, reduces

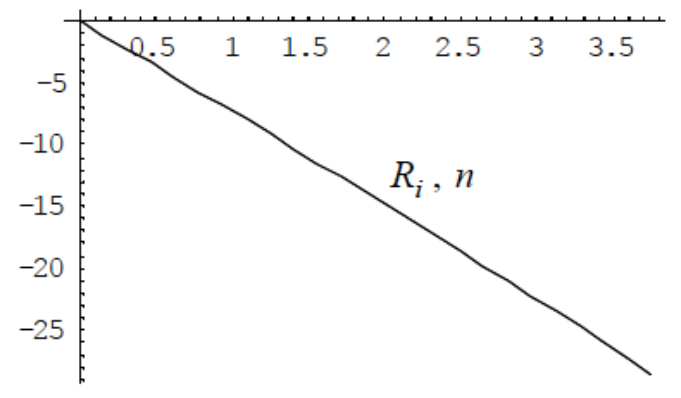

Figure 6: The Effects of a Rise in the Propensity to Use Leisure Time. 
$K, K_{i}, \quad K_{a}, N_{i}, \quad F_{i}, k_{a}, \hat{y}_{i}, \hat{y}_{a}, \bar{k}_{i}, \bar{k}_{a}, c_{i}, c_{a}, n$, $p, R_{i}, w_{a}, R_{a}, \bar{r}$, and does not affect the other variables.

\section{CONCLUDING REMARKS}

This study proposed a spatial growth model by synthesizing the main ideas in the three key models in the neoclassical growth theory and spatial economics. The economic growth with economic geography has a unique equilibrium point when the parameter values are specified. We also analyzed changes in some parameters upon the system.

We have limited our study to a simplified spatial structure of the economic system. Many limitations of this model become apparent in the light of the sophistication of the literature of growth theory, agricultural economics and spatial economics. The Solow model is the key model in the neoclassical economic growth theory and Alonso model is the key model in the modern urban economics. Numerous meaningful extensions of either of the two models have already existed. Zhang (2005) has extended and generalized the neoclassical growth theory in many directions with the utility function used in this study. For instance, following Zhang's models with endogenous knowledge, the spatial economy may have multiple equilibrium structures, which also implies the existence of multiple rent structures over space. There is a large literature on spatial economics (Fujita and Thisse, 2002; Forslid and Ottaviano, 2003; Henderson and Thisse, 2004; Robert-Nicound, 2005). We may introduce more realistic representations of housing market dynamics and transportation systems with congestion. We now point out a few more straightforward extensions. For instance, we may consider the economy as a small country. We may consider a small economy has negligible impact on the interest rate in globally open market. This assumption has been accepted in the literature of international economics. There are many small-country growth models in the literature. With $r$ being fixed, we can examine the residential distribution, land rent distribution, and economic growth by our model. It can be seen that the mathematical analysis becomes easier for an open small economy. Another extension is to assume that the economy is a small and open city in the national economy. In this case, both the utility level and the rate of interest should be exogenously fixed at the national levels. In the literature of the modern urban economics, CBD is no more fixed as assumed in this study. As shown in Fujita and Thisse (2002: Chap. 6), various urban forms can be explained due to communication externalities. See also Imai (1982), Lucas and Rossi-Hansberg (2002), and Berliant, Peng, and Wang (2002) for this direction of research. Moreover, As far as von Thünen's system is concerned, the model does not bear much resemblance to von Thünen's original model. Nevertheless, the model takes account of some features of von Thünen's model. I consider that different agricultural products in von Thünen's model are highly aggregated into a single agricultural product. The high aggregation loses the main feature of von Thünen's original work. This simplification can be relaxed by assuming a variety of agricultural products with the distinct features as in von Thünen's original work, still using the linear system. The essential conclusions of the paper may not be much affected, except some new insights into distribution and production of agricultural products.

\section{APPENDIX: PROVING LEMMA 1}

This study is concerned with equilibrium of the model, as a full dynamic analysis is too complicated. By equations (14) and (19), at equilibrium we have

$s_{j}=\bar{k}_{j}, j=i, a$.

Substitute equations (30) into equations (13) and (18)

$$
\begin{aligned}
& q_{i}(\omega)=\frac{\mu \bar{k}_{i}(\omega)}{\lambda p}, c_{i}(\omega)=\frac{\xi \bar{k}_{i}(\omega)}{\lambda}, \\
& L_{i}(\omega)=\frac{\eta \bar{k}_{i}(\omega)}{\lambda R_{i}(\omega)}, \hat{y}_{i}^{*}(\omega)=\frac{\bar{k}_{i}(\omega)}{\lambda}, \\
& q_{a}=\frac{\mu \bar{k}_{a}}{\lambda p}, c_{a}=\frac{\xi \bar{k}_{a}}{\lambda}, L_{a}=\frac{\eta \bar{k}_{a}}{\lambda R_{a}}, \hat{y}_{a}=\frac{\bar{k}_{a}}{\lambda} .
\end{aligned}
$$

From $\hat{y}_{i}^{*}=\bar{k}_{i} / \lambda, \quad \hat{y}_{a}=\bar{k}_{a} / \lambda$, and the definitions of $\hat{y}_{i}$ and $\hat{y}_{a}$, we solve

$\bar{k}_{i}=\frac{w_{i}+\bar{r}-\Gamma_{c}(\omega)}{f_{r}}$,

$\bar{k}_{a}=\frac{w_{a}+\bar{r}}{f_{r}}$,

in which $f_{r}(r) \equiv 1 / \lambda-1-r$. Substituting equations (A2) and (A3) into the utility functions and then using $U_{i}(0)=U_{i}(\omega)$ and $U_{i}(\omega)=U_{a}$, we obtain 
$\frac{R_{i}(\omega)}{R_{i}(0)}=\left(\frac{\bar{k}_{i}(\omega)}{\bar{k}_{i}(0)}\right)^{(1 / \rho-a) /\left(\eta_{0}-a\right)}\left(\frac{T_{h}(\omega)}{T_{h}(0)}\right)^{\sigma /\left(\eta_{0}-a\right)}$,

$T_{h}^{\sigma}(\omega) \bar{k}_{i}^{1 / \rho-a}(\omega) R_{i}^{a-\eta_{0}}(\omega)=\theta \bar{k}_{a}^{1 / \rho} R_{a}^{-\eta_{0}}, \quad 0 \leq \omega \leq \bar{L}_{i}$,

where

$\theta \equiv \frac{\theta_{a}}{\bar{\theta}_{i}}\left(\frac{\eta}{\lambda}\right)^{a}$

Multiplying the first two equations in (A2) by $n(\omega)$ and then integrate the resulted equations with regard to $\omega$ from 0 to $\bar{L}_{i}$, we have

$\int_{0}^{\bar{L}_{i}} q_{i}(\omega) n(\omega) d \omega=\frac{\mu \bar{K}_{i}}{\lambda p}, \int_{0}^{\bar{L}_{i}} c_{i}(\omega) n(\omega) d \omega=\frac{\xi \bar{K}_{i}}{\lambda}$.

Insert the first equation in (A8) into equation (26)

$\frac{\mu \bar{K}_{i}}{\lambda p}+q_{a} N_{a}=F_{a}$

Substituting $q_{a}=\mu \bar{k}_{a} / \lambda p$ from (A2) into the above equation, we obtain

$\frac{\mu K}{\lambda}=p f_{a} N_{a}$,

where we use equation (28). From equations (2) and (4), we solve

$p f_{a}=\frac{\alpha_{i} k_{a} f_{i}}{\alpha_{a} k_{i}}$.

Substituting equation (A10) into equation (A9) yields

$\frac{K_{i}}{K_{a}}=\alpha_{1} k_{i}^{-\beta_{i}}-1$,

where we also use $K_{a}=k_{a} N_{a}$ and $K_{i}+K_{a}=K$, and $\alpha_{1} \equiv \alpha_{i} \lambda A_{i} / \alpha_{a} \mu$. From equation (A11) and $K_{i}+K_{a}=K$, we solve

$K_{i}=\left(1-\frac{k_{i}^{\beta_{i}}}{\alpha_{1}}\right) K, K_{a}=\frac{k_{i}^{\beta_{i}} K}{\alpha_{1}}$.

From $K_{i}=k_{i} N_{i}$ and the first equation of (A12), we solve

$N_{i}=\left(1-\frac{k_{i}^{\beta_{i}}}{\alpha_{1}}\right) \frac{K}{k_{i}}, N_{a}=N-\left(1-\frac{k_{i}^{\beta_{i}}}{\alpha_{1}}\right) \frac{K}{k_{i}}$, where we use $N_{i}+N_{a}=N$. By $K_{a}=k_{a} N_{a}$ and equations (A12) and (A13), we solve

$k_{a}=\frac{k_{i}^{1+\beta_{i}} K}{\alpha_{1} N k_{i}-\left(\alpha_{1}-k_{i}^{\beta_{i}}\right) K}$.

Using $n=1 / L_{i}$, from equations (A2), we have $R_{i}(\omega)=\eta n(\omega) \bar{k}_{i}(\omega) / \lambda$. Integrating this equation with regard to $\omega$ from 0 to $\bar{L}_{i}$, we have

$\int_{0}^{\bar{L}_{i}} R_{i}(\omega) d \omega=\frac{\eta \bar{K}_{i}}{\lambda}$.

From equations (4) and (A3), we have

$R_{a} L_{0 a}=\varsigma p f_{a} N_{a}, R_{a} L_{a} N_{a}=\frac{\eta \bar{K}_{a}}{\lambda}$.

From equations (6), (7), (A15), (30) and (A16), we have

$\bar{r} N=\frac{\eta K}{\lambda}+\varsigma p f_{a} N_{a}$.

Substitute equation (A10) into the above equation

$\bar{r}=\bar{\eta} K$,

where we also use equations (A12) and $\bar{\eta} \equiv(\eta+\varsigma \mu) / \lambda N$. From equations (23), (25), (A1)-(A3), we obtain

$C=\frac{\xi K}{\lambda}, S=K$.

Substitute these equations into equation (24)

$\left(\frac{\xi}{\lambda}+\delta_{k}\right) K=N_{i} f_{i}$,

where we use $F_{i}=N_{i} f_{i}$. Inserting the equation for $N_{i}$ in equations (A13) into the above equation, we solve

$$
k_{i}=\left\{\left(\frac{\xi}{\lambda}+\delta_{k}\right) \frac{1}{A_{i}}+\frac{1}{\alpha_{1}}\right\}^{-1 / \beta_{i}} .
$$

From equation (A20), we see that we can treat $k_{i}$ as a parameter in the remainder of the proof. From equations (2), we also solve $r$ and $w_{i}$.

From equation (A7), at $\omega=\bar{L}_{i}$ we have 
$T_{h}^{\sigma}\left(\bar{L}_{i}\right) \bar{k}_{i}^{1 / \rho-a}\left(\bar{L}_{i}\right) R_{a}^{a}=\theta \bar{k}_{a}^{1 / \rho}$.

Substitute (A10) into $w_{a}=\beta_{a} p f_{a}$ in (4)

$w_{a}=\frac{w_{0} K}{\alpha_{1} N k_{i}-\left(\alpha_{1}-k_{i}^{\beta_{i}}\right) K}$,

where we use equation (A14) and $w_{0} \equiv \beta_{a} \alpha_{i} k_{i}^{\beta_{i}} f_{i} / \alpha_{a}$. Substitute equations (A17) and (A22) into equations (A4) and (A5)

$\bar{k}_{i}(\omega)=\frac{w_{i}+\bar{\eta} K-\Gamma_{c}(\omega)}{f_{r}}, 0 \leq \omega \leq \bar{L}_{i}$,

$\bar{k}_{a}=\left(\frac{w_{0}}{\alpha_{1} N k_{i}-\left(\alpha_{1}-k_{i}^{\beta_{i}}\right) K}+\bar{\eta}\right) \frac{K}{f_{r}}$,

in which $k_{i}, w_{0}, w_{i}$ and $f_{r}$ are already known. We see that $\bar{k}\left(\bar{L}_{i}\right)$ and $\bar{k}_{a}$ are functions of $K$ and $\bar{L}_{i}$. We now solve $K$ and $\bar{L}_{i}$. Adding the two equations in (A16) yields

$R_{a}=\Lambda_{a}\left(K, \bar{L}_{i}\right) \equiv \frac{\varsigma \alpha_{i} f_{i} K_{a} / \alpha_{a} k_{i}+\eta \bar{K}_{a} / \lambda}{\bar{L}-\bar{L}_{i}}$.

Substitute equations (A23) and (A24) into equation (A21), we have

$T_{h}^{\sigma}\left(\bar{L}_{i}\right)\left[w_{i}+\bar{\eta} K-\Gamma_{c}\left(\bar{L}_{i}\right)\right]^{1 / \rho-a} \Lambda_{a}^{a}\left(K, \bar{L}_{i}\right)=$

$\left(\frac{w_{0}}{\alpha_{1} N k_{i}-\left(\alpha_{1}-k_{i}^{\beta_{i}}\right) K}+\bar{\eta}\right)^{1 / \rho} \frac{\theta K^{1 / \rho}}{f_{r}^{a}}$.

This equation contains two variables, $K$ and $\bar{L}_{i}$. In general, it is impossible to explicitly solve the equation. But if we neglect the travel cost, that is, $\Gamma_{c}\left(\bar{L}_{i}\right)=0$, and assume the urban amenity to be constant, that is, $a=0$, then we can explicitly solve $\bar{L}_{i}$ as a function of $K$. If $a=0$ and $\rho=1$, we can also explicitly solve $\bar{L}_{i}$ as a function of $K$. Without loss of generality, we assume that equation (A25) determines a unique relation between $K$ and $\bar{L}_{i}$, denoted by $\bar{L}_{i}=\Lambda(K)$. We now try to solve $K$.

From equations (A2) and (A6), we obtain

$$
n(\omega)=n(0)\left(\frac{\bar{k}_{i}(\omega)}{\bar{k}_{i}(0)}\right)^{\left(1 / \rho-\eta_{0}\right) /\left(\eta_{0}-a\right)}\left(\frac{T_{h}(\omega)}{T_{h}(0)}\right)^{\sigma /\left(\eta_{0}-a\right)} .
$$

Integrating equation (A26) from 0 to $\bar{L}_{i}=\Lambda(K)$ with regards to $\omega$, we have

$$
\left(1-\frac{k_{i}^{\beta_{i}}}{\alpha_{1}}\right) \frac{K}{k_{i}}=n(0) \int_{0}^{\bar{L}_{i}}\left(\frac{\bar{k}_{i}(\omega)}{\bar{k}_{i}(0)}\right)^{\left(1 / \rho-\eta_{0}\right)\left(\eta_{0}-a\right)}\left(\frac{T_{h}(\omega)}{T_{h}(0)}\right)^{\sigma /\left(\eta_{0}-a\right)} d \omega,
$$

where we also use equations (21) and (A13).

Substitute $R_{i}(\omega)=\eta n(\omega) \bar{k}_{i}(\omega) / \lambda$ from (A2) into equation (A7)

$$
\begin{aligned}
& T_{h}^{\sigma}(\omega) \bar{k}_{i}^{1 / \rho-\eta_{0}}(\omega) n^{a-\eta_{0}}(\omega)=\left(\frac{\lambda}{\eta}\right)^{a-\eta_{0}} \\
& \theta \bar{k}_{a}^{1 / \rho} R_{a}^{-\eta_{0}}, 0 \leq \omega \leq \bar{L}_{i} .
\end{aligned}
$$

Evaluating this equation at $\omega=0$, we have

$$
n(0)=\left(\frac{\lambda}{\eta}\right)\left[\frac{\theta \bar{k}_{a}^{1 / \rho} R_{a}^{-\eta_{0}}}{T_{h}^{\sigma}(0) \bar{k}_{i}^{1 / \rho-\eta_{0}}(0)}\right]^{1 /\left(a-\eta_{0}\right)} .
$$

As $\bar{L}_{i}, K_{a}$ and $\bar{K}_{a}$ are functions of $K$, the righthand side of equation (A24) is a function of $K$. Substituting equation (A24) into equation (A29), we have

$n(0)=\Lambda_{0}(K) \equiv\left(\frac{\lambda}{\eta}\right)\left[\frac{\theta \bar{k}_{a}^{1 / \rho} \Lambda_{a}^{-\eta_{0}}}{T_{h}^{\sigma}(0) \bar{k}_{i}^{1 / \rho-\eta_{0}}(0)}\right]^{1 /\left(a-\eta_{0}\right)}$.

We thus can determine the residential density at the CBD, $n(0)$, as a function of $K$. Substituting equation (A30) into equation (A27), we have

$$
\begin{aligned}
& \Omega(K) \equiv\left(1-\frac{k_{i}^{\beta_{i}}}{\alpha_{1}}\right) \frac{K}{k_{i}}-\Lambda_{0}(K) \\
& \int_{0}^{\bar{L}_{i}(K)}\left(\frac{\bar{k}_{i}(\omega)}{\bar{k}_{i}(0)}\right)^{\left(1 / \rho-\eta_{0}\right) /\left(\eta_{0}-a\right)}\left(\frac{T_{h}(\omega)}{T_{h}(0)}\right)^{\sigma /\left(\eta_{0}-a\right)} d \omega=0 .
\end{aligned}
$$

Equation, $\Omega(K)=0$, contains a single variable, $K$. As it is not easy to explicitly explain conditions for existence of solution, we will demonstrate existence of spatial economic equilibrium by simulation.

\section{ACKNOWLEDGEMENTS}

The author is grateful to the constructive comments of the anonymous referee. The author is also grateful for the financial support from the Grants-in-Aid for Scientific Research (C), Project No. 25380246, and Japan Society for the Promotion of Science. 


\section{REFERENCES}

Abdel-Rahman, H.M. 2004. The City System Paradigm: New Frontiers, in Urban Dynamics and Growth: Advances in Urban Economics, edited by Capello, R. and Nijkamp, P. Amsterdam: Elsevier. http://dx.doi.org/10.1016/S0573-8555(04)66015-9

Abel, A.B. and Bernanke, B.S. 1998. Macroeconomics, $3^{\text {rd }}$ edition. New York: Addison-Wesley.

Alonso, W. 1964. Location and Land Use. MA., Cambridge: Harvard University Press.

http://dx.doi.org/10.4159/harvard.9780674730854

Anas, A. 1990. "Taste Heterogeneity and Urban Spatial Structure: The Logit Model and Monocentric Theory Reconciled." Journal of Urban Economics 28: 318-35. http://dx.doi.org/10.1016/0094-1190(90)90031-H

Arnott, R.J. 1980. "A Simple Urban Growth Model with Durable Housing." Regional Science and Urban Economics 10: 5376. http://dx.doi.org/10.1016/0166-0462(80)90048-4

Baldwin, R.E. and Martin, P. 2004. Agglomeration and Regional Growth. in Handbook of Regional and Urban Economics, Vol. 4, edited by J.V. Hendersson and J.F. Thisse. Amsterdam: Elsevier.

Becker, R.A. 1992. Cooperative Capital Accumulation Games and the Core, in Economic Theory and International Trade: Essays in Memoriam, J. Trout Rader, edited by W. Neuefeind, and R.G. Riezman. Berlin: Springer-Verlag. http://dx.doi.org/10.1007/978-3-642-77671-7 1

Beckmann, M.J. 1957. On the Distribution of Rent and Residential Density in Cities. Paper presented at the inter-Departmental Seminar on Mathematical Applications in the Social Sciences, Yale University.

Beckmann, M.J. 1969. "On the Distribution of Urban Rent and Residential Density." Journal of Economic Theory 1: 60-7. http://dx.doi.org/10.1016/0022-0531(69)90012-X

Beckmann, M.J. and Papageorgiou, Y.Y. 1989. "Heterogeneous Tastes and Residential Location." Journal of Regional Science 29, 317-23. http://dx.doi.org/10.1111/j.1467-9787.1989.tb01381.x

Berliant, M., Peng, S.K. and Wang, P. 2002. "Production Externalities and Urban Configuration." Journal of Economic Theory 104, 275-303.

http://dx.doi.org/10.1006/jeth.2001.2847

Blaug, M. 1985. Economic Theory in Retrospect, fourth edition. Cambridge: Cambridge University Press.

Brueckner, J. K. and Fansler, D. A. 1983. The Economics of Urban Sprawl: Theory and Evidence on the Spatial Sizes of Cities. Review of Economics and Statistics 65: 79-482. http://dx.doi.org/10.2307/1924193

Burmeister, E. and Dobell, A.R. 1970. Mathematical Theories of Economic Growth. London: Collier Macmillan Publishers.

Capello, R. and Nijkamp, P. 2004, edited. Urban Dynamics and Growth: Advances in Urban Economics. Amsterdam: Elsevier.

Carrión-Flores, C. and Irwin, E.G. 2004. "Determinants of Residential Land-Use Conversion and Sprawl at the Rural-Urban Fringe." American Journal of Agricultural Economics 86: 889-904. http://dx.doi.org/10.1111/j.0002-9092.2004.00641.x

De Palma, A., Kilani, M. and Lindsey, R. 2005. "Congestion Pricing on a Road Network: A Study Using the Dynamic Equilibrium Simulator METROPOLIS." Transportation Research A 39: 588-611. http://dx.doi.org/10.1016/j.tra.2005.02.018

Forslid, R. and Ottaviano, G.I.P. 2003. "An Analytically Solvable Core-Periphery Model." Journal of Economic Geography 3: 229-40.

http://dx.doi.org/10.1093/jeg/3.3.229
Frederick, S., Loewenstein, G. and O'Donoghue, T. 2002. "Time Discontinuing and Time Preference: A Critical Review." Journal of Economic Literature 40: 351-401. http://dx.doi.org/10.1257/jel.40.2.351

Fujita, M. 1999. Urban Economic Theory - Land Use and City Size. Cambridge: Cambridge University Press.

Fujita, M. and Thisse, J.F. 2002. Economics of Agglomeration: Cities, Industrial Location, and Regional Growth. Cambridge: Cambridge University Press. http://dx.doi.org/10.1017/CBO9780511805660

Glaeser, E.L., Kolko, J., and Saiz, A. 2001. "Consumer City.” Journal of Economic Geography 1: 27-50. http://dx.doi.org/10.1093/jeg/1.1.27

Henderson, J.V. 1974. "The Sizes and Types of Cities." American Economic Review 64: 640-56.

Henderson, J.V. 1985. Economic Theories and Cities. New York: Academic Press.

Henderson, J.V. and Thisse, J.F. eds. 2004. Handbook of Regional and Urban Economics. Amsterdam: Elsevier.

Imai, H. 1982. "CBD Hypothesis and Economies of Agglomeration." Journal of Economic Theory 28: 275-99. http://dx.doi.org/10.1016/0022-0531(82)90062-X

Isard, W. 1956. Location and Space Economy. MA., Cambridge: MIT Press.

Krugman, P. 1991. "Increasing Returns and Economic Geography." Journal of Political Economy 99: 483-499. http://dx.doi.org/10.1086/261763

Krugman, P. 1998. "Space: The Final Frontier." Journal of Economic Perspectives 12: 161-74. http://dx.doi.org/10.1257/jep.12.2.161

Lucas, R.E. 1988. "On the Mechanics of Economic Development." Journal of Monetary Economics 22: 3-42. http://dx.doi.org/10.1016/0304-3932(88)90168-7

Lucas, R.E. and Rossi-Hansberg, E. 2002. "On the Internal Structure of Cities." Econometrica 70: 1445-76. http://dx.doi.org/10.1111/1468-0262.00338

Mohring, H. 1961. "Land Values and the Measurement of Highway Benefits." Journal of Political Economy 69: 236-249. http://dx.doi.org/10.1086/258466

Mundlak, Y. 2000. Agriculture and Economic Growth: Theory and Measurement. Mass., Cambridge: Harvard University Press.

Muth, R.F. 1961. "The Spatial Structure of the Housing Market." Papers and Proceedings of the Regional Science Association 7: 207-220.

Papageorgiou, Y.Y. and Pines, D., eds. 1999. An Essay on Urban Economic Theory. Boston: Kluwer Academic Publishers. http://dx.doi.org/10.1007/978-1-4615-4947-5

Rader, T. 1981. "Utility over Time: The Homothetic Case." Journal of Economic Theory 25: 219-36. http://dx.doi.org/10.1016/0022-0531(81)90003-X

Ready, R.C. and Abdalla, C.W. 2005. "The Amenity and Disamenity Impacts of Agriculture: Estimates

Richardson, B.V., 1973. Regional Growth Theory. New York: John Wiley.

Rietveld, P., Button, K. and Nijkamp, P., eds. 2003. Urban Transport. Cheltenham: Edward Elgar.

Robert-Nicound, F. 2004. "The Structure of Simple 'New Economic Geography' Models (or, On Identical Twins)." Journal of Economic Geography 5: 201-34. http://dx.doi.org/10.1093/jnlecg/lbh037

Samuelson, P.A. 1937. "A Note on Measurement of Utility." Review of Economic Studies 4: 155-61. http://dx.doi.org/10.2307/2967612

Solow, R. 1956. "A Contribution to the Theory of Growth." Quarterly Journal of Economics 70: 65-94. http://dx.doi.org/10.2307/1884513 
Solow, R.M. 1973. "On Equilibrium Models of Urban Location." in Essays in Modern Economics, edited by M. Parkin. London: Longman.

Steigum, E.Jr. 1984. "Intersectoral Transfer of Labour in a Small Open Economy." European Economic Review 24: 225-37. http://dx.doi.org/10.1016/0014-2921(84)90110-7

Swan, T.W. 1956. "Economic Growth and Capital Accumulation." Economic Record 32: 334-61. http://dx.doi.org/10.1111/j.1475-4932.1956.tb00434.x

Tabuchi, T. and Thisse, J.F. 2002. "Taste Heterogeneity, Labor Mobility and Economic Geography." Journal of Development Economics 69: 155-77. http://dx.doi.org/10.1016/S0304-3878(02)00057-3

Train, K. and McFadden, D. 1978. "The Goods/Leisure Tradeoff and Disaggregate Work Trip Mode Choice Models." Transportation Research 12: 349-53. http://dx.doi.org/10.1016/0041-1647(78)90011-4

Upton, C. 1981. "An Equilibrium Model of City Sizes." Journal of Urban Economics 10: 15-36. http://dx.doi.org/10.1016/0094-1190(81)90020-6

von Thünen, J.H. 1826. Der Isolierte Staat in Beziehung auf Landwirtschaft und Nationalekonomie. Hamburg.
Wheaton, W.C. 2004. "Commuting, Congestion, and Employment Dispersal in Cities with Mixed Land Use." Journal of Urban Economics 55: 417-438. http://dx.doi.org/10.1016/j.jue.2003.12.004

Warner, J.T. and Pleeter, S. 2001. "The Personal Discount Rate: Evidence from Military Downsizing Programs." American Economic Review 91: 33-53. http://dx.doi.org/10.1257/aer.91.1.33

Wigno, L., Jr. 1961. Transportation and Urban Land. Washington, DC.: Resources for the Future.

Zhang, W.B. 1994. "Capital, Population and Urban Patterns." Regional Science and Urban Economics 24: 273-86. http://dx.doi.org/10.1016/0166-0462(93)02037-4

Zhang, W.B. 2005. Economic Growth Theory. Hampshire: Ashgate.

Zhang, W.B. 2007. "Economic Geography and Transportation Conditions with Endogenous Time Distribution amongst Work, Travel, and Leisure." Journal of Transport Geography 15: 476-93.

http://dx.doi.org/10.1016/j.jtrangeo.2007.01.001

Zhang, W.B. 2008. International Trade Theory: Capital, Knowledge, Economic Structure, Money and Prices over Time and Space. Berlin: Springer.

Received on 09-05-2014

Accepted on 11-06-2014

Published on 11-08-2014

DOI: http://dx.doi.org/10.6000/1929-7092.2014.03.21

(C) 2014 Wei-Bin Zhang; Licensee Lifescience Global.

This is an open access article licensed under the terms of the Creative Commons Attribution Non-Commercial License (http://creativecommons.org/licenses/by-nc/3.0/) which permits unrestricted, non-commercial use, distribution and reproduction in any medium, provided the work is properly cited. 